\title{
Ovulation-selective genes: the generation and characterization of an ovulatory-selective cDNA library
}

\author{
A Hourvitz ${ }^{1,2^{*}}$, E Gershon ${ }^{2 *}$, J D Hennebold ${ }^{1}$, S Elizur ${ }^{2}$, \\ E Maman $^{2}$, C Brendle ${ }^{1}$, E Y Adashi ${ }^{1}$ and N Dekel ${ }^{2}$
} ${ }^{1}$ Division of Reproductive Sciences, Department of Obstetrics and Gynecology, University of Utah Health Sciences Center, Salt Lake City, Utah 84132, USA
${ }^{2}$ Department of Biological Regulation, Weizmann Institute of Science, Rehovot, Israel
(Requests for offprints should be addressed to N Dekel; Email: nava.dekel@weizmann.ac.il)
*(A Hourvitz and E Gershon contributed equally to this paper)
(J D Hennebold is now at Division of Reproductive Sciences, Oregon National Primate Research Center, Oregon Health and Science University, Beaverton,
Oregon 97006, USA)

\begin{abstract}
Ovulation-selective/specific genes, that is, genes preferentially or exclusively expressed during the ovulatory process, have been the subject of growing interest. We report herein studies on the use of suppression subtractive hybridization ( $\mathrm{SSH}$ ) to construct a 'forward' ovulationselective/specific cDNA library. In toto, 485 clones were sequenced and analyzed for homology to known genes with the basic local alignment tool (BLAST). Of those, 252 were determined to be nonredundant. Of these 252 nonredundant clones, 98 were analyzed by probing mouse preovulatory and postovulatory ovarian cDNA. Twentyfive clones (26\%) failed to show any signal, and 43 cDNAs tested thus far display a true ovulation-selective/specific expression pattern. In this communication, we focus on one such ovulation-selective gene, the fatty acid elongase 1
\end{abstract}

(FAE-1) homolog, found to be localized to the inner periantral granulosa and to the cumulus granulosa cells of antral follicles. The FAE-1 gene is a $\beta$-ketoacyl-CoA synthase belonging to the fatty acid elongase (ELO) family, which catalyzes the initial step of very long-chain fatty acid synthesis. All in all, the present study accomplished systematic identification of those hormonally regulated genes that are expressed in the ovary in an ovulation-selective/specific manner. These ovulationselective/specific genes may have significant implications for the understanding of ovarian function in molecular terms and for the development of innovative strategies for both the promotion of fertility and its control.

Journal of Endocrinology (2006) 188, 531-548

\section{Introduction}

The individual phases of the normal ovarian life cycle are controlled by a highly synchronized and exquisitely timed cascade of gene expression (Richards 1994, Richards et al. 1995). Ovulation, a complex process initiated by the proestrous surge of luteinizing hormone $(\mathrm{LH})$, constitutes the ultimate step in the maturation of the ovarian follicle and of the oocyte. Once initiated, a cascade of events transpires which culminates in the disintegration of the follicular wall and the release of a fertilizable oocyte. This complex series of events inevitably involves specific ovarian cell types, diverse signaling pathways and temporally controlled expression of specific genes (summarized in Richards 1994, Richards et al. 1998, 2002a, 2002b, Espey $\&$ Richards 2002). Ovulatory genes (genes with increased ovarian expression in the 12 -h interval between the triggering of ovulation and actual follicular rupture) have been the subject of growing interest. The critical importance of some ovulation-selective/specific genes (such as C/EBP- $\beta$, Cox-2 or the progesterone receptor) to murine ovarian function was unequivocally established through the generation of null mutants characterized by ovulatory failure and consequent female sterility (Lydon et al. 1995, 1996, Matzuk et al. 1995, Sterneck et al. 1997, Rankin et al. 1998, Matzuk \& Lamb 2002). These observations underlie the hypothesis that ovulationselective/specific genes constitute critical molecular determinants of ovarian function. Thus far, the isolation and identification of such ovulation-selective/specific genes have proceeded on a case-by-case basis. In the last few years, advanced technologies, such as differential display/ RT-PCR (DD RT/PCR) and DNA microarrays, have been applied, leading to the identification of new ovulatory genes. Using the DD RT/PCR method, Espey and his colleagues were able to identify 30 novel genes, all upregulated during the ovulatory process (Espey et al. 2000a, 2000b, 2000c, 2001, Robker et al. 2000a, 
Ujioka et al. 2000, Yoshioka et al. 2000, Espey \& Richards 2001). These LH-inducible genes included, among others, carbonyl reductase, 3a-hydroxysteroid dehydrogenase $(3 \alpha H S D)$, a regulator of $G$ protein signaling (RGS-2), tumor necrosis factor-induced gene-6 (TSO-6) and early growth regulator-1 (Egr-1). Even though the exact role of these genes in the ovulatory process is not clear yet, their diverse functions and spatial expression pattern in the ovary reaffirmed the complexity and global nature of the ovulatory process.

Leo et al. (2001), in turn, have used DNA microarray technology. cDNAs prepared from ovarian RNA of rats, before and $6 \mathrm{~h}$ after the ovulatory trigger, were hybridized to DNA microarrays representing 600 known rat genes. Quantitative analysis identified a multitude of regulated genes. Several of these genes were involved in extracellular matrix degradation and in lipid/steroid metabolism. Three of these genes, those encoding C-FABP (cutaneous fatty acid-binding protein), the interleukin-4 receptor alpha chain, and preponociceptin, were validated by Northern blot hybridization analysis and further characterized.

Taken together, these and other studies demonstrate that there is a high diversity of yet uncovered genes involved in the complex process of ovulation. These genes, either restricted in their expression to the ovulatory phase or preferentially expressed during the ovulatory process, constitute critical molecular determinants of the cascade leading to follicular rupture. Therefore, the purpose of this work was to isolate systematically these genes that are expressed in an ovulation-selective/specific manner.

\section{Materials and Methods}

In vivo protocols

Female C57BL/6 mice, 19 days of age upon arrival, were purchased from Jackson Laboratories (Bar Harbor, ME, USA). Mice were initially quarantined for 3 days at the University of Utah Animal Resources Center. The latter adheres to the guidelines outlined by the Animal Welfare Act and by Institutional Animal Care and Use Committee (IACUC) protocols. At 25 days of age, one group of mice $(n=8)$ was killed by $\mathrm{CO}_{2}$ asphyxiation, thereby providing unstimulated ovarian material as well as nonovarian tissues. A second group of mice $(n=38)$ was injected i.p. with 10 IU each of pregnant mare's serum gonadotropin (PMSG; Sigma). At $48 \mathrm{~h}$ after PMSG injection, a group of mice were killed $(n=8)$ to secure ovaries at the preovulatory phase of the reproductive cycle. The remaining mice $(n=24)$ were injected i.p. with 10 IU each of human chorionic gonadotropin (hCG) (Sigma). Subgroups ( $n=6 /$ subgroup) of the latter were killed at 2, 4, 6 and $8 \mathrm{~h}$ after hCG injection. Actual follicular rupture occurs approximately $10-14 \mathrm{~h}$ after the injection of hCG to
PMSG-primed mice (Espey et al. 2000b, Robker et al. 2000a). Therefore, we defined preovulatory ovarian mRNA as one which is extracted from untreated mice and mice primed with PMSG for $48 \mathrm{~h}$. Ovarian mRNA from untreated mice is included in the so-called preovulatory ovarian mRNA so as to minimize the isolation of genes, which are constitutively expressed throughout the reproductive life cycle. The ovulatory ovarian mRNA was represented by the pooled ovarian material collected 2, 4, 6 and $8 \mathrm{~h}$ after hCG. The ovulatory ovarian mRNA was selected, as such, so as to include a wide range of genes induced by hCG. We assumed that most ovulationassociated genes are turned on within $8 \mathrm{~h}$ of hCG administration. Other groups of mice were killed 12, 24 and $48 \mathrm{~h}$ after hCG treatment, the last two representing the 'luteal' phase of the ovarian cycle.

\section{Indomethacin administration and ovulation rate assessment}

We used the antiovulatory agent indomethacin, which blocks prostanoid synthesis, to verify that the new identified ovulatory gene was induced via the prostanoid pathway. A subgroup of mice $(n=6)$ treated with PMSG and hCG was injected with indomethacin. Indomethacin (ICN-190217-25, Costa Mesa, CA, USA) was prepared as previously described (Espey et al. 2000b) and was injected s.c. $3 \mathrm{~h}$ after hCG in a dose of $0.7 \mathrm{mg}$ per animal. The ovaries were extracted $8 \mathrm{~h}$ after hCG injection. Another subgroup of 16 animals similarly treated served for ovulation rate assessment. The ovulation rate in the experimental $(n=5)$ animals (treated with PMSG/hCG and indomethacin) and control (PMSG/hCG-treated) animals $(n=5)$ was determined by counting the oviductal ova at $24 \mathrm{~h}$ after hCG administration.

\section{RNA isolation}

Total RNA was isolated from the following nonovarian tissues of immature (25-day) female C57BL/ 6 mice: brain, heart, kidney, liver, spleen, stomach, small intestine, large intestine, adrenal, uterus, muscle, uterus and lung. Total RNA was also isolated from the ovaries of 25-day-old female C57BL/6 mice undergoing the above-mentioned superovulation protocol. The isolation of total RNA was performed with the RNAeasy Kit (Qiagen) according to the manufacturer's directions. PolyA ${ }^{+}$RNA was subsequently isolated with an oligo-dT magnetic sphere-based separation system (RNAatract; Promega).

\section{Suppression subtractive hybridization (SSH)}

SSH was performed with the PCR-Select Kit (Clontech) according to the manufacturer's directions. Briefly, an equal amount of PolyA ${ }^{+}$RNA isolated from each of the preovulatory ovaries was combined to generate a total of $1 \mu \mathrm{g}$ PolyA $^{+}$RNA. This mRNA was used to generate 
the driver cDNA with the SMART cDNA synthesis kit (Clontech) according to the manufacturer's instructions. Ovulatory PolyA ${ }^{+}$RNA $(1 \mu \mathrm{g})$ isolated from mice undergoing the above-described superovulation protocol was used to construct the tester cDNA $(2,4,6$ and $8 \mathrm{~h}$ after hCG). Twenty-five primary and 12 secondary PCR cycles were used to amplify the target (subtracted) ovulatory-selective cDNAs.

\section{Cloning and sequencing of $c \mathrm{DNAs}$}

The PCR products generated by SSH were digested with RsaI to generate blunt ends and to remove the adapters previously ligated to both ends of the target cDNAs. These cDNAs were subsequently purified by the Qiagen PCR system, ligated into the vector pGEM-T Easy (Promega) and transformed into the Epicurian coli strain XL2- Blue MRF' Ultracompetent Cells (Stratagene, San Diego, CA, USA). The individual cDNA inserts were isolated by PCR amplification with flanking T7 and SP6 primer sites. The plasmid template used in the PCR reaction was obtained by direct use of the bacterial cultures lysed in $\mathrm{ddH}_{2} \mathrm{O}$ at a dilution of 1:50. Purified/ PCR-amplified cDNAs were sequenced with T7 primers at the DNA-sequencing core facility of the Huntsman Cancer Institute at the University of Utah Health Sciences Center with Perkin Elmer ABI 377 automated sequencers (Boston, MA, USA). After the adapter and vector sequences were trimmed, the obtained sequence data was analyzed for homology with previously characterized mRNA deposited in the National Center for Biotechnology Informatics (NCBI) database, which includes entries from Genbank, European Molecular Biology Laboratory (EMBL), and DNA Database of Japan (DDBJ) databases using the BLASTn program. Clones not matching entries within the nonredundant database were matched to the NCBI EST database.

\section{Analysis of subtraction efficiency}

An equal amount of cDNA from the (presubtraction) tester pool and final SSH-subtracted product were used as a template to amplify the housekeeping gene glyceraldehyde-3-phosphate dehydrogenase (G3PDH). The forward (5'-TGAAGGTCGGTGTGAACGGATTT GGC-3') and reverse G3PDH primers (5'-CATGTAG GCCATGAGGTCCACCAC-3') were used to amplify a $983 \mathrm{bp}$ product within the following PCR parameters: denaturation $-94{ }^{\circ} \mathrm{C}$ for $45 \mathrm{~s}$; annealing $-56{ }^{\circ} \mathrm{C}$ for $45 \mathrm{~s}$; and extension $-72{ }^{\circ} \mathrm{C}$ for $1 \mathrm{~min}$ and $30 \mathrm{~s}$. Samples were removed after the completion of 16, 20, 24 and 28 cycles. The resultant amplicon was resolved on a $2 \%$ agarose gel stained with ethidium bromide.

\section{Northern blot analysis}

Total RNA $(20 \mu \mathrm{g})$ isolated from ovaries at different stages of the superovulation protocol was separated on denaturing 1\% agarose-formaldehyde gels and transferred to nylon membranes (Magna Graph; MSI, Westboro, MA, USA) by the protocol of Sambrook et al. (1989). Before transfer, RNA quality and concentration were assessed by ethidium bromide staining and visualization under UV light. Nylon membranes were prehybridized for $2-6 \mathrm{~h}$ at $42^{\circ} \mathrm{C}$ in 5 SSPE (sodium chloride-sodium phosphate-EDTA), 50\% formamide, 5 Denhardt's solution $(0 \cdot 2 \%$ BSA, $0 \cdot 2 \%$ polyvinylpyrrolidone and $0 \cdot 2 \%$ Ficoll), $0 \cdot 25 \%$ SDS and $100 \mu \mathrm{g} / \mathrm{ml}$ denatured salmon sperm DNA. Probes were generated by radiolabeling individual PCR-amplified cDNA inserts with $5 \mu \mathrm{Ci}\left[{ }^{32} \mathrm{P}\right] \mathrm{dCTP}$ by the random-hexanucleotideprimed, second-strand synthesis method (Rediprime II; Amersham Pharmacia Biotech). The probes were denatured in a boiling water bath for 5 min before quenching with ice. Membranes were hybridized with the relevant probe overnight at $42{ }^{\circ} \mathrm{C}$ in the same (above-mentioned) solution used for prehybridization. Thereafter, membranes were sequentially washed three times for $5 \mathrm{~min}$ at room temperature with 5 SSC (standard saline citrate) and $0.5 \%$ SDS, followed by two washes for $15 \mathrm{~min}$ at $60{ }^{\circ} \mathrm{C}$ with 1 SSC and $0 \cdot 75 \%$ SDS. The blots were ultimately rinsed with 4 SSC. To quantify the extent of hybridization, the membranes under study were exposed to a phosphor screen (Molecular Imager System; Bio-Rad), and the resultant digitized data were analyzed with Molecular Analyst software (Bio-Rad). The membranes were then stripped by heating to $95^{\circ} \mathrm{C}$ in $0.2 \mathrm{SSC} / 0.5 \%$ SDS and reprobed with a ${ }^{32} \mathrm{P}-$ labeled PCR product corresponding to the mouse $\beta$-actin cDNA to correct for possible variation in RNA loading and/or transfer. Each experiment was carried out at least three times with three different sets of animals in an effort to minimize possible errors introduced by a given individual experiment.

\section{Semiquantitative RT-PCR}

First-strand cDNA was synthesized from total ovarian RNA. Briefly, $1 \mu \mathrm{g}$ total RNA and $0.5 \mu \mathrm{g}$ oligo $(\mathrm{dT})_{12-18}$ (Amersham Pharmacia Biotech) were mixed in diethyl ester pyrocarbonic acid (DEPC)-treated water to a final volume of $30 \mu \mathrm{l}$ and heated to $70{ }^{\circ} \mathrm{C}$ for $2 \mathrm{~min}$, and the reaction was finally quenched on ice for $2 \mathrm{~min}$. Reversetranscription reactions (total volume of $50 \mu \mathrm{l}$ ) were carried out with final concentrations of $50 \mathrm{mM}$ Tris- $\mathrm{HCl}(\mathrm{pH}$ 8.3), $15 \mathrm{mM} \mathrm{MgCl}_{2}, 75 \mathrm{mM} \mathrm{KCl}, 1 \mathrm{mM}$ deoxynucleotide triphosphates, 37 units of RNAguard Ribonuclease Inhibitor from human placenta (Amersham Pharmacia Biotech), $10 \mathrm{mM}$ DTT, $0 \cdot 1 \mathrm{mM}$ each deoxynucleotide triphosphates (d-NTP), $0 \cdot 1 \mathrm{mM}$ oligo(dT) ${ }_{12-18}$, and 400 units Moloney murine leukemia virus reverse transcriptase (M-MLV reverse transcriptase; Gibco BRL). This mixture was incubated at $37^{\circ} \mathrm{C}$ for $1 \mathrm{~h}$ and inactivated at $70{ }^{\circ} \mathrm{C}$ (10 min). A 1:20 dilution of the resultant cDNA was stored at $-20{ }^{\circ} \mathrm{C}$ until used. 
cDNAs corresponding to the different experimental time points or different tissues were used for PCR amplification. Included were a primer set for $\beta$-actin (0.5 $\mu \mathrm{M}$ each; forward primer, $5^{\prime}$-CCCCATTGAACAT GGCATTGTTAC-3'; reverse primer, 5'-TTGATGTCA CGCACGATTTCC-3') or fatty acid elongase 1 (FAE-1) homolog $(0.5 \mu \mathrm{M}$ each; forward primer, 5'-CGATAG GTGCTGAATTGTGG-3'; reverse primer, 5'-AGTGG TGGGAAGTCGAATGG-3') in a $25 \mu \mathrm{l}$ reaction volume with $10 \mathrm{mM}$ Tris- $\mathrm{HCl}$ (pH 9.0), $50 \mathrm{mM} \mathrm{KCl,} \mathrm{0 \cdot 1 \%}$ Triton X-100 (Promega), $2.5 \mathrm{mM} \mathrm{MgCl} 2,400 \mu \mathrm{M}$ each d-NTP and 0.625 units of Taq DNA Polymerase (Promega). PCR was performed for 27 cycles (initial denaturation at $94{ }^{\circ} \mathrm{C}$ for $3 \mathrm{~min}$, and then 27 cycles at $94{ }^{\circ} \mathrm{C}$ for $1 \mathrm{~min}, 59^{\circ} \mathrm{C}$ for $1 \mathrm{~min}, 72^{\circ} \mathrm{C}$ for $1 \mathrm{~min}$ and a final incubation at $72{ }^{\circ} \mathrm{C}$ for $7 \mathrm{~min}$ ). The number of cycles used was determined to be in the log phase of the amplification reaction. The reaction mix $(23 \mu \mathrm{l})$ was run on a $1.5 \%$ agarose gel stained with ethidium bromide, and quantified by UV imaging (Gel Doc 1000; Bio-Rad) and Molecular Analyst software (Bio-Rad). Signals corresponding to FAE-1 expression were normalized relative to $\beta$-actin for each sample. Experimental replication of each time point was performed in triplicate for all three sets.

\section{In situ hybridization}

Mouse ovaries were obtained from immature gonadotropinprimed animals (at the indicated time points). Freshly dissected ovaries were immediately fixed in $4 \%$ paraformaldehyde in PBS, overnight, at $4{ }^{\circ} \mathrm{C}$. Paraffin-embedded tissues were sectioned at $10 \mu \mathrm{m}$ and mounted onto polyL-lysine-coated slides. Sections were deparaffinized, rehydrated, rinsed with DEPC water, and digested with proteinase $\mathrm{K}$. The SSH-generated cDNA was ligated into the vector of pGEM-T Easy Vector (Promega). The vector was used to generate digoxigenin (DIG)-labeled RNA antisense/sense probes of a mouse FAE-1 (300 bp) using the Riboprobe-combination system SP6/T7 (Promega) and the DIG RNA labeling mix (Roche). Tissues were hybridized for $16 \mathrm{~h}$ at $60{ }^{\circ} \mathrm{C}$ with $100 \mu \mathrm{l}$ hybridization solution ( $50 \%$ formamide, 1 Denhardt's solution, $5 \mathrm{SSC}, 10 \%$ dextran sulfate, $0.25 \mathrm{mg} / \mathrm{ml}$ tRNA and $0.5 \mathrm{mg} / \mathrm{ml}$ salmon sperm DNA) and $1 \mu \mathrm{g} / \mathrm{ml}$ of the DIG-labeled FAE-1 mouse antisense or sense probe. At the conclusion of the hybridization phase, the sections were washed, treated with ribonuclease $(20 \mu \mathrm{g} / \mathrm{ml}$ RNase A for $30 \mathrm{~min}$, at $37^{\circ} \mathrm{C}$ ), and gradually desalted (2 SSC, $0 \cdot 1$ SSC and Tris). Staining of the sections was performed with anti-DIG antibody (1:500; Roche), conjugated to alkaline phosphatase overnight at $4{ }^{\circ} \mathrm{C}$. Finally, the ovarian sections were washed and incubated with chromogen (Zymed, Eugene, OR, USA) until color appeared. The sections were visualized by an E-800 microscope (Nikon, Kanagawa, Japan).

\section{Statistical analysis}

Each experiment was carried out at least three times with 3-4 mice at each time point. Data points are presented as mean \pm S.E. Statistical significance (Fisher's protected least significance difference) was determined by the analysis of variance (ANOVA) to assess differences between multiple experimental groups. All analyses were performed using Statview for Macintosh (SAS Institute, Cary, NC, USA).

\section{Results}

\section{Generation of the ovulatory $\mathrm{CDNA}$ library}

Ovulatory cDNAs were isolated by SSH. The efficiency of the SSH procedure was determined by PCR amplification of the housekeeping gene G3PDH. In the subtracted (target) ovarian cDNA population, the amount of G3PDH was significantly reduced relative to the unsubtracted ovarian cDNA (Fig. 1). An additional six PCR cycles were required for the subtracted (target) cDNA to achieve the same level of G3PDH amplification as in the unsubtracted ovulatory cDNA. Since PCR amplification is an exponential process, this difference in the number of cycles translates into a 64-fold depletion of G3PDH cDNA in the subtracted ovulatory material.

After the cloning of the individual $\mathrm{SSH}$-generated cDNA products into a plasmid vector and transformation of the latter into the appropriate bacterial host, 485 independent clones were isolated. The individual cDNA inserts were amplified with primers corresponding to plasmid sequences flanking the multiple cloning sites. The individual PCR products were subsequently sequenced.

\section{Sequence analysis of the ovulatory $c D N A s$}

Each sequenced clone was analyzed after trimming the adapter and vector ends, using the BLASTn program. The corresponding accession number of the best match in the publicly accessible, nonredundant database of NCBI, its E probability value, and the degree of matching were recorded (Table 1). Of the 485 clones analyzed, 252 were determined to be nonredundant sequences. All 252 nonredundant clones sequenced shared homology with entries in the nonredundant database of NCBI, although 12 of these clones possessed significant homology to genomic clones only (i.e. BAC clones), and one clone (4-E5) shared the best homology with entries within the NCBI EST database. Except for two rat homologs, all cDNAs were of mouse origin (Table 1).

Validation of the ovulatory expression pattern of the putative (ovulatory) $c D N A s$

To verify that inserts representing subtracted cDNA are expressed in an ovulatory manner, preovulatory ovarian mRNA (48 $\mathrm{h}$ after the administration of PMSG) 


\section{Unsubtracted}

\section{PCR Cycle \# : $28 \quad 24 \quad 2016$}

G3PDH

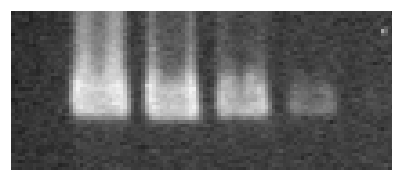

\section{Subtracted}

28242016

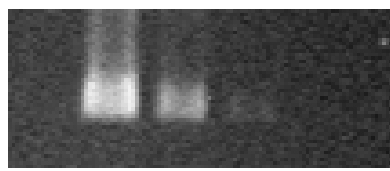

Figure $1 \mathrm{SSH}$ subtraction efficiency was determined by analyzing the amount of G3PDH (housekeeping gene) present in both the unsubtracted starting CDNA and subtracted (ovulatory) target cDNA through the use of increasing numbers of PCR cycles.

and ovulatory ovarian mRNA (2, 4, 6 and $8 \mathrm{~h}$ after hCG) were subjected to Northern blot analysis. Confirmation of equivalent cDNA loading was accomplished by probing for the housekeeping gene $\beta$-actin. To date, we have analyzed 98 genes. In this analysis, 25 clones (26\%) failed to show any signal. Of the 73 hybridizations with a positive signal, 30 clones (41\%) displayed an ovulationselective expression, in that their expression proved higher after hCG than their limited expression $48 \mathrm{~h}$ after PMSG. Thirteen clones (18\%) were determined to have an ovulation-specific expression pattern, in that their expression occurred after hCG administration only, without any signal $48 \mathrm{~h}$ after PMSG. Thirty clones were observed to hybridize equivalently to both preovulatory and ovulatory cDNA populations, thereby giving a false-positive rate of $41 \%$. The full list of genes isolated from the SSH-derived ovulation ovulation-selective cDNA library and confirmed thus far to be expressed in an ovulation-dependent manner is described in Table 2.

The phase-specific expression pattern of two ovulationselective genes, RFG and protease-nexin 1(Spi4), and two ovulation-specific genes, male sterility domain containing 2 (Mlstd2) and BC042477, are presented in Fig. 2. An additional gene, the FAE-1 homolog, was selected for further evaluation. The expression of FAE-1 signal was very low in the preovulatory ovarian RNA samples, but was significantly $(P<0 \cdot 05)$ increased $4 \mathrm{~h}$ after hCG administration. Specifically, the FAE-1 transcript gradually increased up to a peak of approximately $2 \cdot 4$-fold at $12 \mathrm{~h}$ after hCG relative to ovaries preceding hCG treatment (Fig. 3). Equivalent RNA loading was verified by reprobing the same membrane for $\beta$-actin transcripts.

\section{FAE-1 homolog: a representative ovulatory gene}

The cDNA fragment of the FAE-1 is $362 \mathrm{bp}$. This cDNA fragment is highly homologous $(E-v a l u e=0)$ with a segment of the mouse FAE-1 gene, accession nos
AK085696, AK085663, AK051580, AK045274, AK031743, AK028761 and AK004319, which was originally cloned from Mus musculus embryos, skin and mammary glands. Additionally, a fragment of the FAE-1 gene has homology with a gene named ELOVL family member 5 (Elov15; accession nos. NM_134255 and BC022911).

The effect of indomethacin administration on ovulation rate and FAE-1 homolog expression

To confirm the anticipated effect of indomethacin, a prostaglandin synthesis inhibitor, on ovulation rate, parallel groups of animals were treated with or without an inhibitory dose of indomethacin $3 \mathrm{~h}$ after hCG administration. The mean ovulation rate (oocytes numbers) in the 24-h post-hCG control animals (without indomethacin) was $42 \cdot 75 \pm 5 \cdot 30$ as compared with $5 \cdot 20 \pm 1 \cdot 13$ in the 24-h indomethacin-treated animals (Fig. 4A). Moreover, in the control group, all the animals ovulated (8/8), while in the $24-\mathrm{h}$ indomethacin-treated animals only $5 / 8$ animals ovulated. Taken together, these data confirm the ovulation inhibitory effect of indomethacin injection.

Semiquantitative RT-PCR was performed on RNA that had been extracted from control ovaries $8 \mathrm{~h}$ after treatment of the animals with hCG and from experimental ovaries taken $8 \mathrm{~h}$ after hCG from mice treated with an inhibitory dose of indomethacin $(0.7 \mathrm{mg}$ per mouse) $3 \mathrm{~h}$ after hCG. The mRNA expression level (normalized against $\beta$-actin controls) at $8 \mathrm{~h}$ after hCG for ovarian FAE-1 mRNA in animals treated with the antiovulatory agent indomethacin was $104 \%$, which was not significantly different from the 8-h control value (Fig. 4B).

\section{Mouse tissue-specific FAE-1 gene expression}

To assess the FAE-1 gene expression in diverse mouse tissues, RNA was extracted from 14 different tissues and subjected to semiquantitative RT-PCR analysis with specific primers of this gene. As shown in Fig. 5, FAE-1 
Table 1 List of the mRNA/EST corresponding to the clones isolated from the SSH-derived (target) ovulation-selective cDNA library

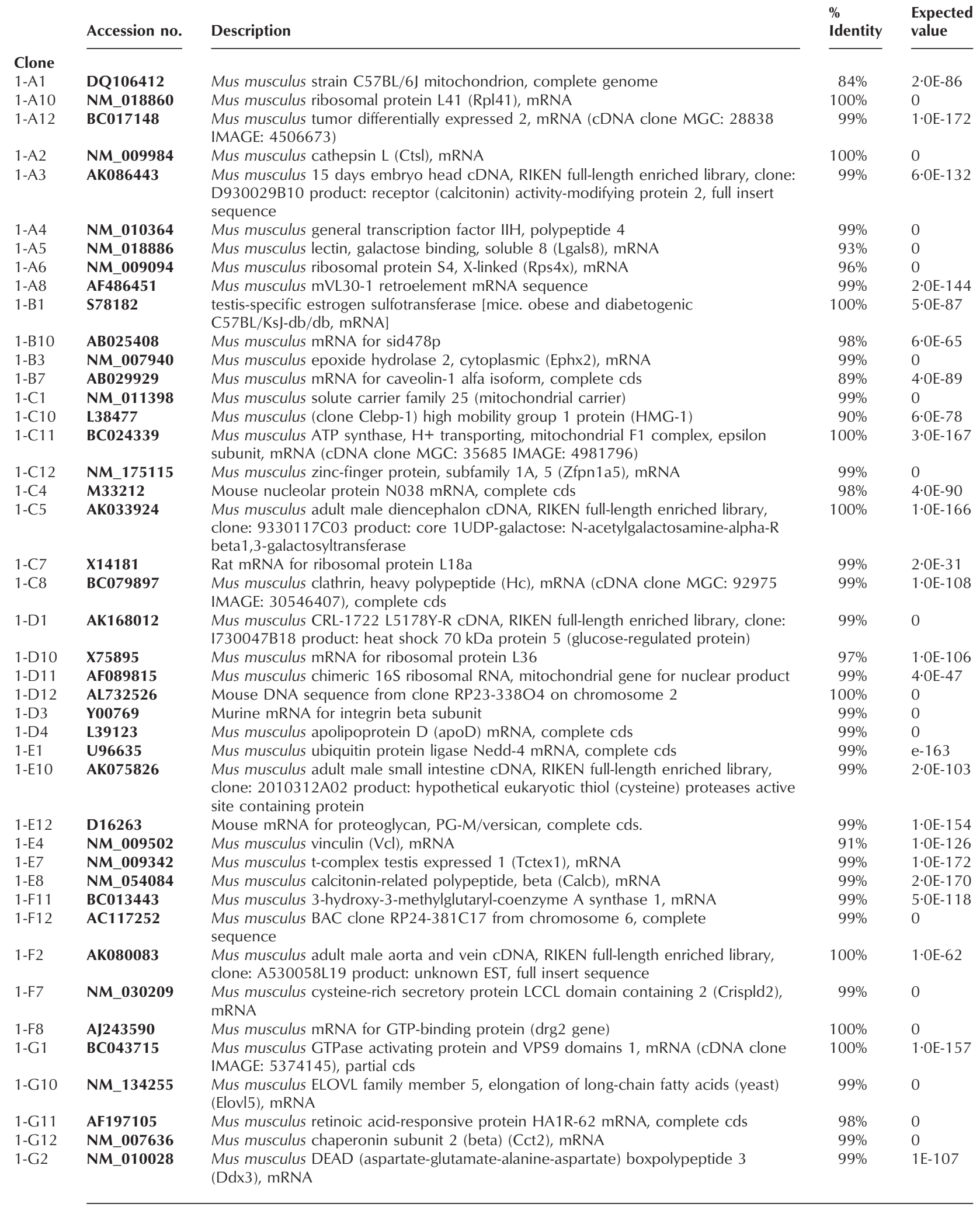


Table 1 Continued

Accession no. Description

$\begin{array}{ll}\text { Clone } & \\ 1-G 6 & \text { BC042477 } \\ & \\ 1-G 7 & \text { AK075685 } \\ & \\ 1-\mathrm{H} 11 & \text { NM_009609 } \\ 1-\mathrm{H} 4 & \text { DQ106413 } \\ 1-\mathrm{H} 5 & \text { NM_011899 } \\ 1-\mathrm{H} 6 & \text { NM_009145 } \\ 1-\mathrm{H} 8 & \text { BC021765 }\end{array}$

2-A1 NM 007950

2-A4 NM_010448

2-A7 AJ001006

2-A9 AK077784

2-B1 NM_010324

2-B3 X75926

2-B4 X80159

2-B7 NM_007585

2-B8 X16053

2-B9 NM_008218

2-C11 AL596331

2-C12 NM_008809

2-C2 NM 133753

2-C4 NM_025505

2-C8 NM_145546

2-C9 AK169217

2-D1 NM 010480

2-D11 BC049271

2-D12 NM_008615

2-D4 AC126455

2-D7 AC115718

2-D8 NM_026030

2-E1 BC025583

2-E4 BC071194

2-E5 BC056378

2-E7 $\quad \mathbf{M 1 8 6 7 8}$

2-E8 AF120319

2-E9 NM_009398

2-F10 NM_011723

2-F11 NM_008582

2-F12 XM_355303

2-F2 NM_025844

2-F3 NM_008816

2-F7 NM_009255

2-F8 NM_008669

2-F9 BC082283

2-G1 X17124

2-G12 BC038614

2-G2 AB033922

2-G4 NM_026448

2-G7 AC115039

2-G8 NM_026931

mRNA mRNA
Mus musculus RIKEN cDNA 1200016E24 gene, mRNA (cDNA clone IMAGE:

4189100), partial cds

Mus musculus 18-day embryo whole-body cDNA, RIKEN full-length enriched library, clone: $1190001 \mathrm{H} 13$ product: FNP001 homolog [Homo sapiens], full insert sequence Mus musculus actin, gamma, cytoplasmic (Actg), mRNA

Mus musculus strain VM mitochondrion, complete genome

Mus musculus signal recognition particle $54 \mathrm{kDa}$ (Srp54), mRNA

Mus musculus stromal cell derived factor receptor 1 (Sdfr1), mRNA

Mus musculus high-density lipoprotein (HDL) binding protein, mRNA (cDNA clone

MGC: 8000 IMAGE: 3585871), complete cds

Mus musculus epiregulin (Ereg), mRNA

Mus musculus heterogeneous nuclear ribonucleoprotein A/B (Hnrpab), mRNA

Mus musculus mRNA for EMeg32 protein

Mus musculus adult male thymus CDNA, RIKEN full-length enriched library, clone:

5830454D03 product: unknown EST, full insert sequence

Mus musculus glutamate oxaloacetate transaminase 1 , soluble (Got1), mRNA

Mus musculus abc1 mRNA

Mus musculus CW17 mRNA

Mus musculus calpactin I heavy chain (Cal1h), mRNA

Mouse mRNA for thymosin beta-4

Mus musculus hemoglobin alpha, adult chain 1 (Hba-a1), mRNA

Mouse DNA sequence from clone RP23-81G14 on chromosome 11

Mus musculus platelet derived growth factor receptor, beta polypeptide (Pdgfrb),

Mus musculus RIKEN cDNA 1300002F13 gene (1300002F13Rik), mRNA

Mus musculus basic leucine zipper nuclear factor 1 (Blzf1), mRNA

Mus musculus general transcription factor IIB (Gtf2b), mRNA.

Mus musculus 17-day embryo stomach cDNA, RIKEN full-length enriched library,

clone: 1920091H01 product: ribosomal protein L9

Mus musculus heat-shock protein, 86 kDa 1 (Hsp86-1), mRNA

Mus musculus solute carrier family 38 , member 2, mRNA

Mus musculus malic enzyme, supernatant (Mod1), mRNA

Mus musculus BAC clone RP23-260P2 from chromosome 16

Mus musculus chromosome 8, clone RP23-247P3

Mus musculus eukaryotic translation initiation factor 2, subunit 2 (beta) (Eif2s2),

Mus musculus lamin B receptor, mRNA (cDNA clone IMAGE: 5324962), containing frame-shift errors

Mus musculus leukocyte receptor cluster (LRC) member 4, mRNA

Mus musculus ATP citrate lyase, mRNA (cDNA clone MGC: 73502 IMAGE:

6850252), complete cds

Mouse histone $\mathrm{H} 3 \cdot 3$ pseudogene (MH-921), complete cds

Mus musculus MTV-3 regulated mRNA sequence

Mus musculus tumor necrosis factor induced protein 6 (Tnfip6), mRNA

Mus musculus xanthine dehydrogenase (Xdh), mRNA

Mus musculus maternal embryonic message 3 (Mem3), mRNA

Predicted: Mus musculus RIKEN cDNA $1700029 F 09$ gene (1700029F09Rik), mRNA

Mus musculus cysteine and histidine-rich domain (CHORD)-containing, zinc-binding protein 1 (Chordc1)

Mus musculus platelet/endothelial cell adhesion molecule (Pecam), mRNA

Mus musculus protease-nexin 1 (serine protease inhibitor 4 (Spi4)), mRNA

Mus musculus $\mathrm{N}$-acetyl galactosaminidase, alpha (Naga), mRNA

Mus musculus steroidogenic acute regulatory protein, mRNA (cDNA clone MGC:

90948 IMAGE: 30436512), complete cds

Mouse DNA for virus-like (VL30) retrotransposon BVL-1

Mus musculus cDNA clone IMAGE: 4459248

Mus musculus mRNA for $\mathrm{Ndr} 1$ related protein $\mathrm{Ndr} 3$, complete cds

Mus musculus kelch-like 7 (Drosophila) (Klhl7), mRNA

Mus musculus chromosome 6, clone RP24-279C2, complete sequence

Mus musculus RIKEN cDNA 1810011010 gene (1810011O10Rik), mRNA
$\%$

Identity

$99 \%$

$2 \mathrm{E}-113$

$99 \%$

$3 \cdot 0 \mathrm{E}-92$

$99 \%$

$99 \%$

$98 \%$

$96 \%$

$100 \%$

$100 \%$

$100 \%$

$99 \%$

$100 \%$

$\begin{array}{rl}97 \% & \text { e-128 } \\ 99 \% & 0 \\ 100 \% & 0 \\ 98 \% & \mathrm{e}-144 \\ 98 \% & 0 \\ 99 \% & \mathrm{e}-140 \\ 100 \% & 3 \cdot 0 \mathrm{E}-101 \\ 99 \% & 2 \cdot 0 \mathrm{E}-99\end{array}$

$99 \%$

$100 \%$

$100 \%$

$100 \%$

0

4.0E-31

8.0E-128

$1 \cdot 0 \mathrm{E}-173$

$99 \% \quad 0$

$99 \% \quad 8 \cdot 0 \mathrm{E}-150$

$96 \% \quad 0$

$100 \% \quad 2 \cdot 0 \mathrm{E}-116$

$100 \% \quad 6 \cdot 0 \mathrm{E}-109$

$97 \% \quad 0$

$99 \% \quad 0$

$100 \% \quad 3 \cdot 0 \mathrm{E}-87$

$100 \% \quad 7 \cdot 0 \mathrm{E}-81$

$99 \% \quad 9 \cdot 0 \mathrm{E}-77$

$100 \% \quad \mathrm{e}-166$

99\% e-149

99\% e-129

98\% e-173

$99 \% \quad 2 \cdot 0 \mathrm{E}-131$

$100 \% \quad 4 \cdot 0 \mathrm{E}-78$

$\begin{array}{rl}99 \% & 0 \\ 100 \% & 1 \cdot 0 \mathrm{E}-75 \\ 99 \% & 0 \\ 99 \% & 0 \\ 99 \% & 0 \\ 100 \% & 7 \cdot 0 \mathrm{E}-168 \\ 98 \% & 0 \\ 99 \% & 0 \\ 100 \% & 9 \cdot 0 \mathrm{E}-137 \\ 100 \% & 0\end{array}$


Table 1 Continued

Accession no.

Clone

2-G9

2- $\mathrm{H} 11$

$2-\mathrm{H} 7$

2-H8

3-A1

3-A11

3-A4

3-A8

3-A9

3-B1

3-B12

3-B3

3-B5

3-C10

3-C11

3-C4

$3-\mathrm{C} 5$

3-C6

3-D1

3-D11

3-D2

3-D4

3-D8

3-D9

3-E1

3-E10

3-E11

3-E12

3-E3

3-E8

3-E9

3-F11

3-F2

3-F4

3-F5

3-F7

3-G12

3-G3

3-G6

$3-\mathrm{H} 1$

3- $\mathrm{H} 10$

3- $\mathrm{H} 11$

3-H3 NM_027959

4-A11 NM_026143

NM_026444

BC083074

NM 007568

NM_027379

X67268

BC061023

AK168008

NM 008576

BC066048

NM_133925

NM 134081

NM_175121

NM_024197

BC028892

NM_007594

NM_172015

AY771618

AJ002636

AK028147

AC141896

BC011111

NM_009673

NM 028173

BC023924
Description

Mus musculus tenascin C (Tnc), mRNA

Mus musculus MT transposon-like element clone MTi6

Mus musculus adult male olfactory brain cDNA, RIKEN full-length enriched library,

clone: $6430549 \mathrm{~L} 24$ product: RNA binding motif protein 4, full insert sequence

Mus musculus stearoyl-coenzyme A desaturase $2(\operatorname{Scd} 2)$, mRNA

Mus musculus nuclear-encoded mitochondrial steroidogenic acute regulatory protein

(Star) mRNA, complete cds

Mouse t complex polypeptide 1 (Tcp-1-b) mRNA, complete cds

Mus musculus tubulin alpha 6 (Tuba6), mRNA

Murine mRNA with homology to yeast L29 ribosomal protein gene

Mus musculus caveolin-2 mRNA, complete cds

Mus musculus glutathione-S-transferase, mu 2 (Gstm2), mRNA

Mus musculus guanine nucleotide binding protein, alpha inhibiting 3, mRNA (cDNA

clone MGC: 46956 IMAGE: 2648164), complete cds

Mus musculus RIKEN cDNA 1810055G02 gene (1810055G02Rik), mRNA

Mus musculus sorting nexin 2, mRNA (cDNA clone MGC: 6322 IMAGE: 2812557)

Mus musculus type 1 tumor necrosis factor receptor shedding aminopeptidase regulator, mRNA (CDNA clone MGC: 54451 IMAGE: 6397585), complete cds

Mus musculus preimplantation protein 3, mRNA (cDNA clone MGC: 68122 IMAGE: 4980300)

Mus musculus ovary-selective epoxide hydrolase (Ovseh) mRNA

Mus musculus citrate synthase (Cs), mRNA

NM_001025309

AK081521

Mus musculus non-POU-domain-containing, octamer binding protein, mRNA (cDNA clone MGC: 103109 IMAGE: 6390386), complete cds

Mus musculus betacellulin, epidermal growth factor family member, (Btc), mRNA

Mus musculus male sterility domain containing 2 (Mlstd2), mRNA

Mus musculus gas5 growth arrest specific gene, exons 4-12

Mus musculus six transmembrane epithelial antigen of the prostate 1, mRNA (cDNA clone MGC: 74129 IMAGE: 30304473), complete cds

Mus musculus CRL-1722 L5178Y-R cDNA, RIKEN full-length enriched library, clone:

1730046O10 product: farnesyl diphosphate synthetase

Mus musculus ATP-binding cassette, subfamily C (CFTR/MRP), member 1 (Abcc1), mRNA

Mus musculus peroxisome proliferative activated receptor, gamma, coactivator-related 1, mRNA

Mus musculus RNA binding motif protein 28 (Rbm28), transcript variant 2, mRNA

Mus musculus Dnal (Hsp40) homolog, subfamily C, member 9 (Dnajc9), mRNA

Mus musculus solute carrier family 38, member 2 (Slc38a2), mRNA

Mus musculus NADH dehydrogenase (ubiquinone) 1 alpha subcomplex 10

(Ndufa10), mRNA

Mus musculus cDNA sequence BC024806, mRNA (cDNA clone IMAGE: 3673713),

with apparent retained intron

Mus musculus calumenin (Calu), mRNA

Mus musculus isoleucine-tRNA synthetase (lars), mRNA

Mus musculus praja 2, RING-H2 motif containing (Pja2), transcript variant 1, mRNA

Mus musculus olfactorin (Umodl1) mRNA, complete cds, alternatively spliced

Mus musculus 16 days embryo head cDNA, RIKEN full-length enriched library, clone:

C130030E18 product: FBJ osteosarcoma oncogene B, full insert sequence

Mus musculus mRNA for nuclear protein SA2

Mus musculus adult male tongue cDNA, RIKEN full-length enriched library, clone:

2310032 I17 product: very large G protein-coupled receptor 1 fragment, full insert sequence

Mus musculus BAC clone RP23-238B2 from 5

Mus musculus signal sequence receptor, gamma, mRNA

Mus musculus annexin A5 (Anxa5), mRNA.

Mus musculus translocating chain-associating membrane protein 1 (Tram1), mRNA

Mus musculus phytoceramidase, alkaline, mRNA (cDNA clone MGC: 36600 IMAGE:

5324078), complete cds

Mus musculus protein disulfide isomerase associated 6 (Pdia6), mRNA

Mus musculus male sterility domain containing 2 (Mlstd2), transcript variant 1, mRNA
$\%$

Identity

Expected

value

$100 \%$

$99 \%$

$100 \%$

$96 \%$

$99 \%$

$98 \%$

$100 \%$

99\%

98\%

99\%

99\%

99\%

$100 \%$

$98 \%$

$99 \%$

$99 \%$

$99 \%$

$100 \%$

$100 \%$

$99 \%$

99\%

$99 \%$

$98 \%$

$87 \%$

$100 \%$

$99 \%$

$99 \%$

99\%

99\%

$99 \%$

$99 \%$

$99 \%$

$99 \%$

$100 \%$

$99 \%$

$99 \%$

$98 \%$

$2 \cdot 0 \mathrm{E}-74$

$6 \cdot 0 \mathrm{E}-129$

99\%

$100 \%$

99\%

99\%

3.0E-74

6.0E-51

e-116

1.0E-125

99\%

5.0E-154

99\%

$100 \%$

$$
0
$$


Table 1 Continued

Accession no. Description

\begin{tabular}{|c|c|}
\hline Clone & \\
\hline 4-A2 & NM_01165 \\
\hline $4-\mathrm{A} 3$ & AY940477 \\
\hline $4-\mathrm{A} 6$ & NM_013725 \\
\hline $4-A 7$ & M60285 \\
\hline $4-A 8$ & AK008300 \\
\hline 4-A9 & NM_008810 \\
\hline 4-B10 & ВC070470 \\
\hline 4-B11 & AJ272504 \\
\hline 4-B12 & M58567 \\
\hline 4-B3 & $\mathrm{X} 13460$ \\
\hline 4-B5 & ВC005537 \\
\hline 4-B6 & AL627204 \\
\hline $4-B 7$ & NM_008972 \\
\hline 4-B8 & NM_026155 \\
\hline 4-B9 & AF090401 \\
\hline 4-C1 & NM_178693 \\
\hline 4-C10 & AC142274 \\
\hline 4-C2 & NM_009610 \\
\hline 4-C4 & NM_024221 \\
\hline 4-C6 & NM_025703 \\
\hline $4-C 7$ & AY040780 \\
\hline 4-C9 & AF159461 \\
\hline 4-D10 & NM_010497 \\
\hline 4-D5 & NM_024437 \\
\hline 4-D6 & U69135 \\
\hline 4-D7 & AF074881 \\
\hline 4-D8 & NM_008379 \\
\hline 4-D9 & ВС004805 \\
\hline 4-E3 & NM_130860 \\
\hline 4-E4 & AC126272 \\
\hline 4-E5 & CV971482 \\
\hline 4-E7 & NM_17229 \\
\hline 4-E8 & BC064729 \\
\hline 4-F5 & NM_009413 \\
\hline 4-F7 & NM_178610 \\
\hline 4-G12 & NM_017372 \\
\hline & ВС043118 \\
\hline $4-\mathrm{H} 1$ & NM_011966 \\
\hline
\end{tabular}

4-H10 NM_028472

4-H4 NM_009458

4-H6 BC055117

4-H7 NM 207634

5-A11 AK156331

\section{5-A3 U17089}

5-A4 J04134

5-A5 NM_025623

5-A9 NM_028279

5-B10 NM_012053

5-B11 BC003900 mRNA mRNA
Mus musculus tubulin, beta 5 (Tubb5), mRNA

Mus musculus strain C57BL/6 endogenous retrotransposon VL30x-2 mRNA

Mus musculus ribosomal protein S11 (Rps11), mRNA.

Mouse cAMP-responsive element modulator (CREM) mRNA, complete cds

Mus musculus adult male small intestine cDNA, RIKEN full-length enriched library, clone: 2010100012 product: hypothetical protein

Mus musculus pyruvate dehydrogenase E1 alpha 1 (Pdha1), mRNA

Mus musculus autophagy-related 12-like (yeast), mRNA (cDNA clone MGC: 99425

IMAGE: 30630196), complete cds

Mus musculus mRNA for Sh3bgrl protein

Mus musculus delta-5-3-beta-hydroxysteroid dehydrogenase/delta-5->delta-4

isomerase (Hsd3b) mRNA, complete cds

Mouse mRNA for p68 protein of the lipocortin family

Mus musculus RIKEN cDNA 8030460C05 gene, mRNA (cDNA clone MGC: 8156

IMAGE: 3589775), complete cds

Mouse DNA sequence from clone RP23-118E21 on chromosome 4

Mus musculus prothymosin alpha (Ptma), mRNA

Mus musculus signal sequence receptor, gamma (Ssr3), mRNA

Mus musculus QKI protein ( $\mathrm{qkl}$ ) gene, alternative splice product

Mus musculus coenzyme Q4 homolog (yeast) (Coq4), mRNA

Mus musculus BAC clone RP23-251M14 from 6, complete sequence

Mus musculus actin, gamma 2, smooth muscle, enteric (Actg2), mRNA

Mus musculus pyruvate dehydrogenase (lipoamide) beta (Pdhb), mRNA

Mus musculus transcription elongation factor A (SII)-like 8 (Tceal8), mRNA.

Mus musculus forkhead-associated domain histidine-triad like protein mRNA

Mus musculus RFG (Rfg) mRNA, complete cds

Mus musculus isocitrate dehydrogenase 1 (NADP+), soluble (Idh1), mRNA

Mus musculus nudix (nucleoside diphosphate linked moiety X)-type motif 7 (Nudt7),

transcript variant 1 , mRNA.

Mus musculus UCP2 mRNA, complete cds

Mus musculus strain $\mathrm{C} 3 \mathrm{H}$ histone deacetylase 3 (Hdac3) mRNA, complete cds.

Mus musculus importin beta (Impnb), mRNA

Mus musculus cDNA clone IMAGE: 3584831

Mus musculus cyclin-dependent kinase 9 (CDC2-related kinase) (Cdk9), mRNA.

Mus musculus BAC clone RP23-48P22 from chromosome 14, complete sequence

LRRGE01481 Liver regeneration after partial hepatectomy Rattus norvegicus cDNA,

Mus musculus sulfatase 1 (Sulf1), mRNA

Mus musculus astacin-like metalloendopeptidase (M12 family), mRNA (cDNA clone

MGC: 76457 IMAGE: 30476764), complete cds

Mus musculus tumor protein D52-like 1 (Tpd52l1), mRNA

Mus musculus HIV-1 Rev binding protein 2 (Hrb2), mRNA

Mus musculus lysozyme (Lyzs), mRNA

Mus musculus cDNA sequence BC043118, mRNA (cDNA clone MGC: 58045)

Mus musculus proteasome (prosome, macropain) subunit, alpha type 4 (Psma4),

Mus musculus BMP-binding endothelial regulator (Bmper), mRNA

Mus musculus ubiquitin-conjugating enzyme E2B (RAD6 homology) (Ube2b), mRNA

Mus musculus angiomotin-like 1, mRNA (cDNA clone IMAGE: 6504557)

Mus musculus ribosomal protein S24 (Rps24), transcript variant 2, mRNA

Mus musculus activated spleen cDNA, RIKEN full-length enriched library, clone:

F830016M19 product: actin, alpha 2, smooth muscle, aorta, full insert sequence

Mus musculus MT transposon-like element, clone MTi7

Mouse brain calmodulin-dependent phosphatase (calcineurin) catalytic subunit mRNA, 3' end

Mus musculus nipsnap homolog 3A (C. elegans) (Nipsnap3a), mRNA

Mus musculus $\mathrm{N}$-acetylated alpha-linked acidic dipeptidase 2 (Naalad2), mRNA

Mus musculus ribosomal protein L8 (Rpl8), mRNA

Mus musculus DNA segment, Chr 15, ERATO Doi 785, expressed, mRNA (cDNA

clone MGC: 6766 IMAGE: 3601298), complete cds

\begin{tabular}{|c|c|}
\hline $\begin{array}{l}\% \\
\text { Identity }\end{array}$ & $\begin{array}{l}\text { Expected } \\
\text { value }\end{array}$ \\
\hline $99 \%$ & 0 \\
\hline $98 \%$ & $3 \cdot 0 \mathrm{E}-161$ \\
\hline $99 \%$ & $1 \cdot 0 \mathrm{E}-86$ \\
\hline $99 \%$ & 0 \\
\hline $100 \%$ & 0 \\
\hline $99 \%$ & $4 \cdot 0 \mathrm{E}-121$ \\
\hline $99 \%$ & $8 \cdot 0 \mathrm{E}-122$ \\
\hline 100\% & $1 \cdot 0 \mathrm{E}-44$ \\
\hline $98 \%$ & e-170 \\
\hline $98 \%$ & 0 \\
\hline $100 \%$ & $3 \cdot 0 \mathrm{E}-60$ \\
\hline $100 \%$ & $7 \cdot 0 \mathrm{E}-84$ \\
\hline $99 \%$ & e-107 \\
\hline $99 \%$ & 0 \\
\hline $95 \%$ & e-173 \\
\hline $100 \%$ & 0 \\
\hline $100 \%$ & 0 \\
\hline $99 \%$ & e-160 \\
\hline $100 \%$ & $7 \cdot 0 \mathrm{E}-52$ \\
\hline 100\% & $5 \cdot 0 \mathrm{E}-68$ \\
\hline $99 \%$ & 0 \\
\hline $98 \%$ & 0 \\
\hline $99 \%$ & $8 \cdot 0 \mathrm{E}-128$ \\
\hline $99 \%$ & $2 \cdot 0 \mathrm{E}-71$ \\
\hline $99 \%$ & 0 \\
\hline $99 \%$ & 0 \\
\hline $96 \%$ & 0 \\
\hline $99 \%$ & 0 \\
\hline $99 \%$ & $4 \cdot 0 \mathrm{E}-107$ \\
\hline $100 \%$ & 0 \\
\hline $100 \%$ & $3 \cdot 0 \mathrm{E}-58$ \\
\hline $100 \%$ & 0 \\
\hline $99 \%$ & 0 \\
\hline $99 \%$ & 0 \\
\hline $99 \%$ & 0 \\
\hline $99 \%$ & 0 \\
\hline $99 \%$ & 0 \\
\hline $99 \%$ & 0 \\
\hline $100 \%$ & 0 \\
\hline $99 \%$ & $3 \cdot 0 \mathrm{E}-95$ \\
\hline $100 \%$ & 0 \\
\hline 100\% & 0 \\
\hline $100 \%$ & $1 \cdot 0 \mathrm{E}-103$ \\
\hline $97 \%$ & 0 \\
\hline $99 \%$ & e-105 \\
\hline $99 \%$ & 0 \\
\hline $99 \%$ & $6 \cdot 0 \mathrm{E}-106$ \\
\hline $99 \%$ & 0 \\
\hline $99 \%$ & $6 \cdot 0 \mathrm{E}-90$ \\
\hline
\end{tabular}


Table 1 Continued

Accession no.

$\begin{array}{ll}\text { Clone } & \\ \text { 5-B3 } & \text { NM_011354 } \\ & \\ \text { 5-B4 } & \text { NM_007512 } \\ \text { 5-B5 } & \text { NM_016750 } \\ & \\ \text { 5-B6 } & \text { AK157911 }\end{array}$

5-B8 AK005710

5-C10

5-C11

5-C2

5-C4

5-C5

$5-\mathrm{C} 6$

5-C9

5-D1

5-D2

5-D3

5-D7

5-D8

5-E2

5-E3

5-E4

5-E9

5-F2

5-F4

$5-\mathrm{F} 6$

5-F7

5-F9

5-G1

5-G10

5-G6

$5-\mathrm{H} 10$

5- 44

$5-\mathrm{H} 7$

6-A6

6-A8

6-B10

6-B12

6-B4

6-B5

6-B6

6-B7

6-B9

6-C2

AF209906

NM_010286

AC122285

D83037

NM_008112

NM_029657

NM 145556

AB016248

AK136528

AF145253

NM_133808

NM_145220

AF195119

NM_025959

NM_008594 AK140139

NM_029814

NM_026069

NM_009283

U14172

NM_011300

AK136760

AK012966

NM_008885

NM_008302

BC043055

NM_010122

D31717

NM_009655

AL731826

L20294

NM_025295

AK040977

M93980

AK088923
Description

Mus musculus small EDRK-rich factor 2 (Serf2), and testis-specific estrogen sulfotransferase mRNA

Mus musculus ATPase inhibitor (Atpi), mRNA

Mus musculus histone H2A.Z (H2afz), and Mus musculus SHYC (Shyc) mRNA, complete cds mRNA

Mus musculus adult inner ear cDNA, RIKEN full-length enriched library, clone: F930007F18 product: hypothetical Zn-finger, RING/Zinc finger RING-type profile containing protein

Mus musculus adult male testis cDNA, RIKEN full-length enriched library, clone: 1700007G02 product: solute carrier family 25 (mitochondrial deoxynucleotide carrier), member 19

AB025217 Mus musculus mRNA for Sid470p, complete cds

Mus musculus receptor activity modifying protein 2 mRNA, complete

Mus musculus glucocorticoid-induced leucine zipper (Gilz), mRNA

Mus musculus BAC clone RP23-251G4 from 14, complete sequence

Mouse mRNA for 14-3-3 zeta, complete cds/phospholipase A2

Mus musculus guanosine diphosphate (GDP) dissociation inhibitor 3 (Gdi3), mRNA

Mus musculus mahogunin, ring finger 1 (Mgrn1), mRNA

Mus musculus TAR DNA-binding protein (Tardbp), transcript variant

Mus musculus mRNA for sterol-C5-desaturase, complete cds

Mus musculus adult male cecum cDNA, RIKEN full-length enriched library, clone:

9130025I01 product: hypothetical protein (expressed sequence AW557061)

(3-alpha-hydroxysteroid dehydrogenase)

Mus musculus Sec61 alpha isoform 1 mRNA, complete cds

Mus musculus high-density lipoprotein (HDL) binding protein (Hdlbp), mRNA

Mus musculus Dip3 beta (Dip3b), mRNA

Mus musculus cytochrome P450 side chain cleavage enzyme 11a1 (Cyp11a) mRNA, complete cds

Mus musculus proteasome (prosome, macropain) 26S subunit, ATPase, 6 (Psmc6), mRNA

Mus musculus milk fat globule-EGF factor 8 protein (Mfge8), mRNA

Mus musculus adult male corpora quadrigemina cDNA, RIKEN full-length enriched library, clone: B230312D24 product: zinc finger transcription factor ZNF207 homolog [Mus musculus]

Mus musculus chromatin modifying protein 5 (Chmp5), mRNA

Mus musculus ribosomal protein L37 (Rpl37), mRNA

Mus musculus signal transducer and activator of transcription 1(Stat1), mRNA

Mus musculus p162 protein mRNA, complete cds

Mus musculus ribosomal protein S7 (Rps7), mRNA

Mus musculus adult male diencephalon cDNA, RIKEN full-length enriched library, clone: 9330001D09 product

Mus musculus 10, 11 days embryo whole body cDNA, RIKEN full-length enriched library, clone: 2810402G08 product

Mus musculus peripheral myelin protein, $22 \mathrm{kDa}(\mathrm{Pmp} 22)$, mRNA

Mus musculus heat-shock protein 1, beta (Hspcb), mRNA

Mus musculus SH3-binding domain glutamic acid-rich protein-like, mRNA (cDNA clone MGC: 57957 IMAGE: 6418767)

Mus musculus eukaryotic translation initiation factor 2B (Eif2b), mRNA

Mouse MARib mRNA for ribophorin, complete cds

Mus musculus activated leukocyte cell adhesion molecule (Alcam)

Mouse DNA sequence from clone RP23-123012 on chromosome 2

Mus musculus GTP-binding protein (mSara) homologue mRNA, complete cds

Mus musculus biotinidase (Btd), mRNA

Mus musculus adult male aorta and vein cDNA, RIKEN full-length enriched library,

clone: A530054J02 product

Mouse 24.6 kda protein mRNA, complete cds

Mus musculus 2 days neonate thymus thymic cells cDNA, RIKEN full-length enriched

library, clone: E430031K14 product: nucleophosmin 1

Mouse gene for alpha-globin
$\%$

Identity

Expected

value

$100 \%$

e-121

$98 \%$

$99 \%$

0

$1 \cdot 0 \mathrm{E}-77$

$100 \%$

0

$100 \%$

0

$100 \%$

$100 \%$

$95 \%$

$99 \%$

$100 \%$

$100 \%$

$99 \%$

$99 \%$

$96 \%$

$99 \%$

$100 \%$

99\%

$100 \%$

95\%

$98 \%$

$100 \%$

$100 \%$

$7 \cdot 0 \mathrm{E}-81$

4.0E-136

$100 \%$

$100 \%$

$100 \%$

99\%

$99 \%$

$100 \%$

0

0

3.0E-71

0

e-123

3.0E-137

$99 \% \quad 0$

$100 \%$

$99 \%$

$100 \%$

e-151

3.0E-111

7.0E-96

$100 \%$

$100 \%$

$99 \%$

$100 \%$

$97 \%$

$100 \%$

$100 \%$

e-159

0

0

9.0E-103

3.0E-71

0

$97 \%$

3.0E-123

$99 \%$

0

$100 \%$
2.0E-103

1.0E-29 
Table 1 Continued

Accession no. Description

\begin{tabular}{ll} 
Clone & \\
\cline { 2 - 2 } 6-C3 & AK042369 \\
& \\
6-C5 & M12660 \\
6-C6 & NM_016687 \\
6-D2 & BC057115 \\
& \\
6-D3 & AK050031 \\
& \\
6-D5 & AK084373 \\
6-E11 & NM_026911 \\
6-E2 & AK003408 \\
6-E4 & M22432 \\
& \\
6-E9 & BC017603 \\
6-F5 & NM_145360 \\
6-F7 & AF155355 \\
6-G1 & NM_025564 \\
6-G10 & M27073 \\
6-G12 & NM_177992 \\
6-G2 & NM_011085 \\
6-G3 & NM_016769 \\
6-G4 & NM_013916 \\
6-G5 & NM_026845 \\
6-G6 & BC083315 \\
6-H10 & K02109 \\
6-H2 & BC026424 \\
6-H5 & NM_145933 \\
6-H6 & BC030344 \\
AK020134
\end{tabular}
6406330) mRNA

3673521)
Mus musculus 3 days neonate thymus cDNA, RIKEN full-length enriched library, clone: A630085G14 product: weakly similar to LETHAL (3) 82FD PROTEIN [Dosophila melanogaster] Mouse CFh locus, complement protein $\mathrm{H}$ gene, complete cds, clones $\mathrm{MH}(4,8)$ Mus musculus secreted frizzled-related sequence protein 4 (Sfrp4), mRNA Mus musculus SWI/SNF related, matrix associated, actin dependent regulator of chromatin, subfamily a, member 1, mRNA (cDNA clone MGC: 63228 IMAGE:

Mus musculus adult male liver tumor cDNA, RIKEN full-length enriched library, clone: C730004P03 product: hypothetical ubiquitin domain containing protein

Mus musculus 12-day embryo eyeball cDNA, RIKEN full-length enriched library, clone: D230034D01 product: hypothetical protein

Mus musculus signal peptidase complex subunit 1 homolog (S. cerevisiae) (Spcs1),

Mus musculus 18-day embryo whole-body cDNA, RIKEN full-length enriched library, clone: 1110004D14 product: similar to AD024 [Homo sapiens]

Mus musculus protein synthesis elongation factor Tu (eEF-Tu, eEf-1-alpha) mRNA, complete cds

Mus musculus thioredoxin domain containing 1, mRNA (cDNA clone MGC: 27603 IMAGE: 4503129)

Mus musculus isopentenyl-diphosphate delta isomerase (Idi1), mRNA

Mus musculus ankyrin repeat-containing protein Asb-4 mRNA, complete cds

Mus musculus RIKEN cDNA 2010012C16 gene (2010012C16Rik), mRNA

(Mago-Nashi)

Mus musuculus protein phosphatase type 1 (dis2m2) mRNA, complete cds

Mus musculus guanosine monophosphate reductase 2 (Gmpr2), mRNA

Mus musculus phosphatidylinositol 3-kinase, regulatory subunit, polypeptide 1 (p85 alpha) (Pik3r1), transcript variant 2, mRNA

Mus musculus MAD homolog 3 (Drosophila) (Smad3), mRNA

Mus musculus Hoxa1 regulated gene (Ha1r-pending), mRNA

Mus musculus peptidylprolyl isomerase (cyclophilin)-like 1 (Ppil1), mRNA

Mus musculus NHP2 non-histone chromosome protein 2-like 1 (S. cerevisiae), mRNA

Mouse 3T3-L1 lipid binding protein mRNA, complete cds

Mus musculus prolylcarboxypeptidase (angiotensinase C), mRNA (cDNA clone

IMAGE: 4222343), partial cds

Mus musculus beta galactoside alpha 2,6 sialyltransferase 1(St6gal1), mRNA

Mus musculus thioredoxin-like 5, mRNA (cDNA clone MGC: 40618 IMAGE:

Mus musculus 12-day embryo male wolffian duct includes surrounding region cDNA, RIKEN full-length enriched library, clone: 6720458D04 product: receptor (calcitonin) activity-modifying protein 2

\begin{tabular}{|c|c|}
\hline $\begin{array}{l}\% \\
\text { Identity }\end{array}$ & $\begin{array}{l}\text { Expected } \\
\text { value }\end{array}$ \\
\hline $100 \%$ & $2 \cdot 0 \mathrm{E}-169$ \\
\hline $99 \%$ & e-130 \\
\hline $96 \%$ & $1 \cdot 0 \mathrm{E}-69$ \\
\hline $99 \%$ & 0 \\
\hline $99 \%$ & 0 \\
\hline $99 \%$ & 0 \\
\hline $99 \%$ & 0 \\
\hline $99 \%$ & $2 \cdot 0 \mathrm{E}-119$ \\
\hline $99 \%$ & e-116 \\
\hline $99 \%$ & 0 \\
\hline $99 \%$ & 0 \\
\hline $99 \%$ & 0 \\
\hline $98 \%$ & 0 \\
\hline $100 \%$ & $3 \cdot 0 \mathrm{E}-55$ \\
\hline $99 \%$ & $1 \cdot 0 \mathrm{E}-70$ \\
\hline $99 \%$ & 0 \\
\hline $99 \%$ & $2 \cdot 0 \mathrm{E}-99$ \\
\hline $99 \%$ & 0 \\
\hline $99 \%$ & 0 \\
\hline $99 \%$ & 0 \\
\hline $96 \%$ & $3 \cdot 0 \mathrm{E}-99$ \\
\hline $100 \%$ & $2 \cdot 0 \mathrm{E}-57$ \\
\hline $100 \%$ & 0 \\
\hline $100 \%$ & 0 \\
\hline
\end{tabular}

$99 \% \quad 2 \cdot 0 \mathrm{E}-133$ gene expression could be detected in six of the 14 tissues tested (mouse brain, kidney, adrenal, liver, testis and ovary). The strongest signal was detected in the brain and ovary ( 8 h after hCG). No signal was detected in the heart, spleen, stomach, small intestine, large intestine, uterus, muscle and lung.

\section{Cellular localization of FAE-1 mRNA in PMSG-primed/ hCG-triggered (ovulatory and postovulatory) mouse ovaries}

The signal of the in situ hybridization reaction localized the FAE-1 to the granulosa cells of preovulatory follicles
(Fig. 6). Time-course studies revealed ovarian FAE-1 mRNA expression to rise from undetectable levels at the time of hCG injection ( $48 \mathrm{~h}$ after PMSG) to maximal levels within $12 \mathrm{~h}$ after treatment with hCG, in accordance with the aforementioned Northern blot results.

As shown in Fig. 6, great heterogeneity was noted in labeling intensity among granulosa cells of PMSGprimed/hCG-triggered antral follicles. The message encoding FAE-1 localized exclusively to the inner periantral granulosa (granulosa cells adjacent to the antrum) and to the cumulus cells of developing antral follicles. No detectable signal was noted for the mural granulosa cells. 
Table 2 Genes isolated from the SSH-derived ovulation (target) ovulation-selective cDNA library and confirmed to be expressed in an ovulation-dependent manner

\begin{tabular}{|c|c|c|}
\hline & Accession no. & Description \\
\hline $\begin{array}{l}\text { Clone no. } \\
1-A 1\end{array}$ & DQ106412 & Mus musculus strain $\mathrm{C} 57 \mathrm{BL} / 6 \mathrm{~J}$ mitochondrion, complete genome \\
\hline 1-A12 & ВC017148 & $\begin{array}{l}\text { Mus musculus tumor differentially expressed 2, mRNA (cDNA clone MGC: } 28838 \\
\text { IMAGE: 4506673) }\end{array}$ \\
\hline $1-\mathrm{A} 2$ & NM_009984 & Mus musculus cathepsin L (Ctsl), mRNA \\
\hline $1-\mathrm{A} 3$ & AK086443 & $\begin{array}{l}\text { Mus musculus 15-day embryo head cDNA, RIKEN full-length enrichedlibrary, clone: } \\
\text { D930029B10 product: receptor (calcitonin) activity-modifying protein 2, full insert } \\
\text { sequence }\end{array}$ \\
\hline 1-B3 & NM_007940 & Mus musculus epoxide hydrolase 2, cytoplasmic (Ephx2), mRNA \\
\hline 1-D1 & AK168012 & $\begin{array}{l}\text { Mus musculus CRL- } 1722 \text { L5178Y-R cDNA, RIKEN full-length enriched library, clone: } \\
\text { I730047B18 product: heat-shock } 70 k D a \text { protein } 5 \text { (glucose-regulated protein) }\end{array}$ \\
\hline 1-D3 & Y00769 & Murine mRNA for integrin beta subunit \\
\hline $1-\mathrm{E7}$ & NM_009342 & Mus musculus t-complex testis expressed 1 (Tctex1), mRNA \\
\hline $1-\mathrm{F} 12$ & AC117252 & Mus musculus BAC clone RP24-381C17 from chromosome 6, complete sequence \\
\hline 1-F2 & AK080083 & $\begin{array}{l}\text { Mus musculus adult male aorta and vein cDNA, RIKEN full-length enriched library, } \\
\text { clone: A530058L19 product: unknown EST, full insert sequence }\end{array}$ \\
\hline $1-\mathrm{G} 10$ & NM_134255 & $\begin{array}{l}\text { Mus musculus ELOVL family member 5, elongation of long-chain fatty acids (yeast) } \\
\text { (Elovl5), mRNA }\end{array}$ \\
\hline 1-G2 & NM_010028 & $\begin{array}{l}\text { Mus musculus DEAD (aspartate-glutamate-alanine-aspartate) boxpolypeptide } 3 \text { (Ddx3), } \\
\text { mRNA }\end{array}$ \\
\hline 2-A1 & NM_007950 & Mus musculus epiregulin (Ereg), mRNA \\
\hline 2-A9 & AK077784 & $\begin{array}{l}\text { Mus musculus adult male thymus cDNA, RIKEN full-length enriched library, clone: } \\
\text { 5830454D03 product: unknown EST, full insert sequence }\end{array}$ \\
\hline $2-\mathrm{C} 11$ & AL596331 & Mouse DNA sequence from clone RP23-81G14 on chromosome 11 \\
\hline 2-F12 & XM_355303 & Predicted: Mus musculus RIKEN cDNA 1700029 F09 gene (1700029F09Rik), mRNA \\
\hline 2-F7 & NM_009255 & Mus musculus protease-nexin 1, also known as serine protease inhibitor 4 (Spi4) \\
\hline 2-G12 & ВC038614 & Mus musculus cDNA clone IMAGE: 4459248 \\
\hline 2-G7 & AC115039 & Mus musculus chromosome 6, clone RP24-279C2, complete sequence \\
\hline $3-B 3$ & NM_028077 & Mus musculus RIKEN cDNA $1810055 \mathrm{G} 02$ gene (1810055G02Rik), mRNA \\
\hline 3-D1 & NM_007568 & Mus musculus betacellulin, epidermal growth factor family member, (Btc), mRNA \\
\hline 3-D4 & AF186249 & $\begin{array}{l}\text { Homo sapiens six transmembrane epithelial antigen of prostate (STEAP1) mRNA, } \\
\text { complete cds. }\end{array}$ \\
\hline $3-\mathrm{F} 2$ & NM_001025309 & Mus musculus praja 2, RING-H2 motif-containing (Pja2), transcript variant 1, mRNA \\
\hline 4-C9 & AF159461 & RFG (Rfg) mRNA \\
\hline $4-\mathrm{F} 5$ & NM_009413 & Mus musculus tumor protein D52-like 1 (Tpd52l1), mRNA \\
\hline $4-\mathrm{F} 7$ & NM_178610 & Mus musculus HIV-1 Rev binding protein 2 (Hrb2), mRNA \\
\hline $4-\mathrm{H} 4$ & NM_009458 & Mus musculus ubiquitin-conjugating enzyme E2B (RAD6 homology) (Ube2b), mRNA \\
\hline 5-A9 & NM_028279 & Mus musculus $\mathrm{N}$-acetylated alpha-linked acidic dipeptidase 2 (Naalad2), mRNA \\
\hline 5-E9 & NM_008594 & Mus musculus milk fat globule-EGF factor 8 protein (Mfge8), mRNA \\
\hline 6-G6 & ВС-083315 & Mus musculus NHP2 non-histone chromosome protein 2-like 1 (S. cerevisiae), mRNA \\
\hline 1-B1 & S78182 & $\begin{array}{l}\text { Testis-specific estrogen sulfotransferase (mice, obese and diabetogenic } \\
\text { C57B/LKsJ-db/db, mRNA, } 1273 \mathrm{nt} \text { ) }\end{array}$ \\
\hline $1-\mathrm{C} 1$ & NM_011398 & Mus musculus solute carrier family 25 (mitochondrial carrier) \\
\hline 1-G1 & ВС043715 & $\begin{array}{l}\text { Mus musculus GTPase activating protein and VPS9 domains 1, mRNA (cDNA clone } \\
\text { IMAGE: } 5374145 \text { ), partial cds }\end{array}$ \\
\hline $1-\mathrm{G} 6$ & ВC042477 & $\begin{array}{l}\text { Mus musculus RIKEN cDNA 1200016E24 gene, mRNA (cDNA clone IMAGE: } \\
4189100 \text { ), partial cds }\end{array}$ \\
\hline 2-E9/ 6-D10 & NM_009398 & Mus musculus tumor necrosis factor induced protein 6 (Tnfip6), mRNA \\
\hline 2-F9 & BC082283 & $\begin{array}{l}\text { Mus musculus steroidogenic acute regulatory protein, mRNA (cDNA clone MGC: } \\
90948 \text { IMAGE: } 30436512 \text { ), complete cds }\end{array}$ \\
\hline 3-A11 & M12899 & Mouse t complex polypeptide 1 (Tcp-1-b) mRNA, complete cds \\
\hline 3-D2 & X67268 & Mus musculus gas5 growth arrest-specific gene, exons 4-12 \\
\hline 4-A11 & NM_026143 & Mus musculus male sterility domain containing $2(\mathrm{Mlstd} 2)$, transcript variant $1, \mathrm{mRNA}$ \\
\hline 5-B6 & AK157911 & $\begin{array}{l}\text { Mus musculus adult inner ear cDNA, RIKEN full-length enriched library, clone: } \\
\text { F930007F1 } 8 \text { product: hypothetical Zn-finger, RING/zinc finger RING-type profile } \\
\text { containing protein, full insert sequence }\end{array}$ \\
\hline $6-\mathrm{B} 10$ & NM_009655 & Mus musculus activated leukocyte cell adhesion molecule (Alcam) \\
\hline 6-B6 & AK040977 & $\begin{array}{l}\text { Mus musculus adult male aorta and vein cDNA, RIKEN full-length enriched library, } \\
\text { clone: A530054J02 product }\end{array}$ \\
\hline 6-G1 & NM_025564 & $\begin{array}{l}\text { Mus musculus RIKEN cDNA 2010012C16 gene (2010012C16Rik), mRNA } \\
\text { (Mago-Nashi) }\end{array}$ \\
\hline
\end{tabular}

Northern blot expression

Ovulation-selective Ovulation-selective

Ovulation-selective Ovulation-selective

Ovulation-selective Ovulation-selective

Ovulation-selective Ovulation-selective Ovulation-selective Ovulation-selective

Ovulation-selective

Ovulation-selective

Ovulation-selective Ovulation-selective

Ovulation-selective Ovulation-selective Ovulation-selective Ovulation-selective Ovulation-selective Ovulation-selective Ovulation-selective Ovulation-selective

Ovulation-selective Ovulation-selective Ovulation-selective Ovulation-selective Ovulation-selective Ovulation-selective Ovulation-selective Ovulation-selective Ovulation-specific

Ovulation-specific Ovulation-specific

Ovulation-specific

Ovulation-specific Ovulation-specific

Ovulation-specific Ovulation-specific Ovulation-specific Ovulation-specific

Ovulation-specific Ovulation-specific

Ovulation-specific 


\section{Ovulation-Selective}

A

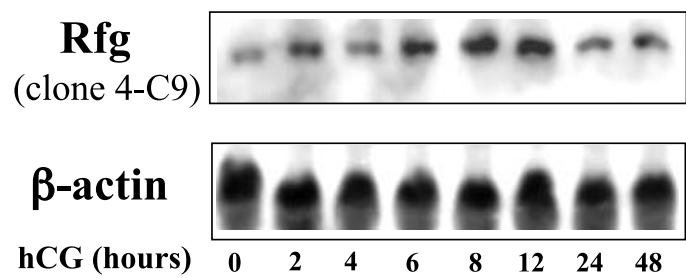

\section{Ovulation-Specific}

C
Mlstd2 (clone 4-A11)

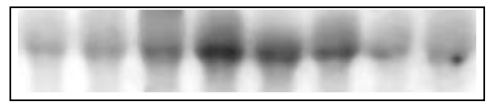

$-2.0 \mathrm{~KB}$

$\beta$-actin

hCG (hours)

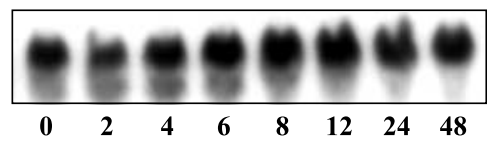

B

\section{Protease-}

Nexin 1

(clone 2-F7)

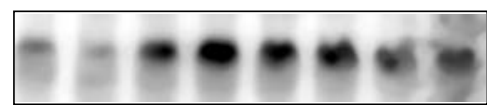

$\beta$-actin

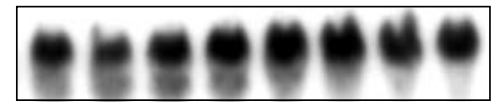

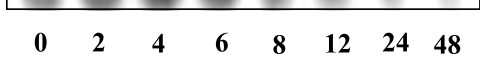

$-5.0 \mathrm{~KB}$

(clone 1-G6)

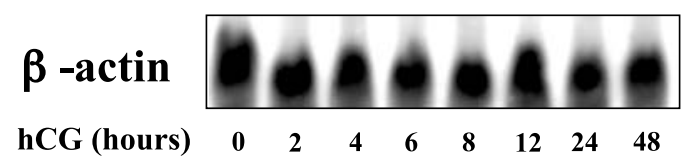

Figure 2 Verification of ovulatory-specific mRNA expression of four subtracted clones by Northern blot analysis. PCR products corresponding to four genes - Rfg (A), protease-nexin 1 (spi4) (B), male sterility domain containing 2 (Mlstd2) (C), and accession no. BC042477 (D) - were radiolabeled and used to probe membranes containing total ovarian RNA ( $20 \mu \mathrm{g} /$ lane) isolated from mice undergoing stimulated ovulation. Equivalent RNA loading was verified by reprobing the membranes with radiolabeled, PCR-amplified $\beta$-actin.

\section{Discussion}

The aim of the current study was to isolate ovulationselective/specific genes in a systematic manner. We report herein studies on the use of the SSH method to construct a 'forward' ovulation-selective/specific cDNA library. In toto, 252 nonredundant clones were sequenced and analyzed. Of those, 98 clones were analyzed by probing mouse preovulatory and postovulatory ovarian cDNA.

We define preovulatory ovarian mRNA as one that was extracted from untreated mice and mice primed with PMSG for $48 \mathrm{~h}$. Ovarian mRNA from untreated mice was included in the preovulatory ovarian mRNA so as to minimize the isolation of genes constitutively expressed throughout the reproductive life cycle. Actual follicular rupture occurs approximately $10-14 \mathrm{~h}$ after the injection of PMSG-primed mice with hCG (Espey 1980, Espey et al. 2000b). In preliminary studies, we found ovulation to occur as early as $8 \mathrm{~h}$ after hCG, peaking at $12-14 \mathrm{~h}$ (data not shown). Therefore, the ovulatory ovarian mRNA was represented by pooled ovarian material collected 2, 4, 6 and $8 \mathrm{~h}$ after hCG. The ovulatory ovarian mRNA was selected, as such, so as to include a wide range of genes induced by hCG. We assumed that most ovulationassociated genes would be expressed within $8 \mathrm{~h}$ after hCG administration.

Several techniques are currently available to identify new genes (Lisitsyn \& Wigler 1993, Schena et al. 1995, Velculescu et al. 1995, Chee et al. 1996, Diatchenko et al. 1999, Espey et al. 2000b, Wang \& Feuerstein 2000).
A

FAE1

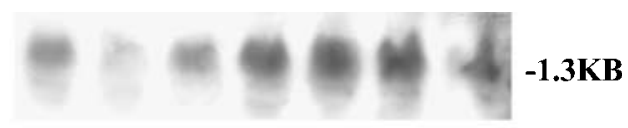

$\beta$-actin

hCG (hours)

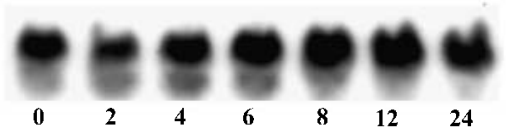

B

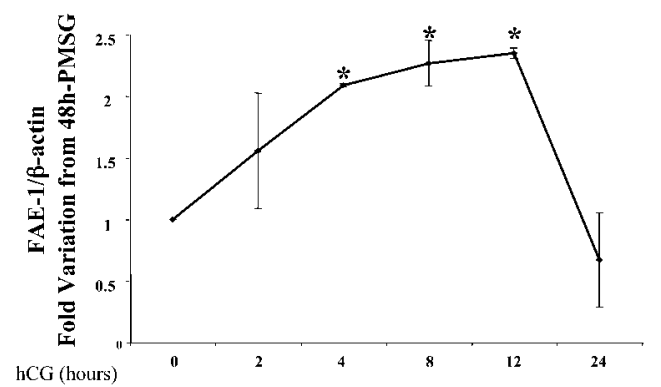

Figure 3 (A) Phase-specific expression of FAE-1 homolog mRNA by Northern blot analysis. PCR products corresponding to FAE-1 were radiolabeled and used to probe a membrane containing total ovarian RNA ( $20 \mu \mathrm{g} / \mathrm{lane})$ isolated from mice undergoing a simulated estrous cycle. Equivalent RNA loading was verified by re-probing the membranes with radiolabeled/PCR-amplified $\beta$-actin. The signal intensities were determined by densitometry. (B) The ratio of FAE- $1 / \mathrm{b}$-actin expression was calculated and compared with expression in the 48-h PMSG ovaries. The data represent the mean \pm S.E.M. of three independent experiments. * indicates statistical significance (ANOVA followed by Fisher's least-squares difference post-hoc analysis, StatView 5.0) of $P<0 \cdot 05$ as compared with the 48-h PMSG samples. 
A

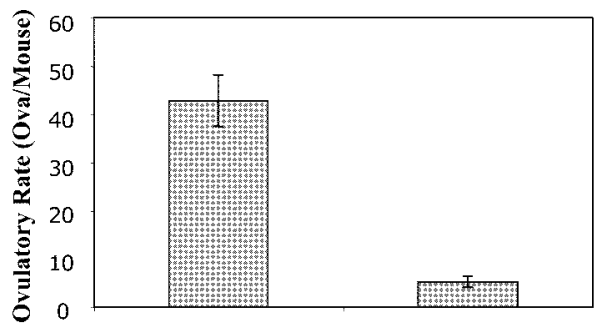

Indomethacin $(0.7 \mathrm{mg} / \mathrm{mouse})$

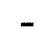

$+$

B

FAE-1

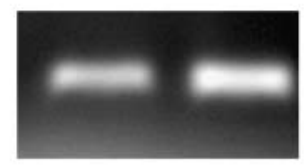

$\beta$-actin

hCG (hours)

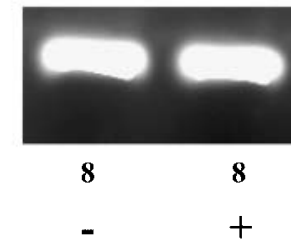

Indomethacin $(0.7 \mathrm{mg} / \mathrm{mouse})$

Figure 4 (A) Inhibitory effect of indomethacin on ovulation. Parallel groups of animals were treated with or without a prostaglandin (PG) synthesis inhibitory dose of indomethacin $3 \mathrm{~h}$ after hCG administration. The ovulation rate was determined $24 \mathrm{~h}$ after hCG by counting ova in the oviducts. The data represent the mean \pm S.E.M. of three independent experiments. (B) Semiquantitative RT-PCR. RNA extracted from ovaries $8 \mathrm{~h}$ after hCG administration from experimental animals that had been treated $3 \mathrm{~h}$ after hCG with an inhibitory dose of indomethacin $(0.7 \mathrm{mg}$ per mouse) was compared with untreated control animals $8 \mathrm{~h}$ after hCG administration. The corresponding ovarian cDNAs were analyzed by semiquantitative RT-PCR as described in Materials and Methods. The resultant PCR product was visualized after electrophoresis on a $1.5 \%$ agarose gel stained with ethidium bromide. Each sample was analyzed in triplicate. The panel shown reflects a representative experiment from a total of three independent experiments.

We chose to use the SSH technique, since the relative advantages of SSH include the fact that it does not rely on an existing cDNA library and therefore is not limited by its quality. Other advantages are the normalization of the representation of high and low abundance transcripts, and the elimination of the physical subtraction step in the isolation of target cDNAs (Lee et al. 2000, Levesque et al. 2003, Fayad et al. 2004, Rebrikov et al. 2004). Moreover, the successful use of this PCR-based method has previously been reported in the context of constructing testis-specific library (Diatchenko et al. 1996) and by our laboratory in constructing an ovary-specific library (Tanaka et al. 2003). The discovery of new ovulatory genes in this study confirms the potential of this technique.

Although the utilization of SSH in the current study successfully yielded previously characterized, ovulationspecific genes (such as tumor necrosis factor-stimulated gene-6, steroidogenic acute regulatory protein (StAR), early growth response protein-1 and $3 \beta-\mathrm{HSDI}$ ), several expected genes were not present within the target cDNA library. For example, C/EBP- $\beta$ (Pall et al. 1997), Cox-2 (Lim et al. 1997, Davis et al. 1999) and the progesterone receptor (Lydon et al. 1995, 1996) were not found within the subtracted ovulation library. The absence of these genes from the library may be due to the fact that the screening of the subtracted ovulation cDNA library was not complete. It also may be due to an incomplete representation of the relevant mRNA in the tester cDNA pool that was used in the subtraction process. Both the tester and driver cDNA pools were generated by the SMART (Switching Mechanism At $5^{\prime}$ end of RNA Transcript) cDNA synthesis kit (Clontech). This process relies on the addition of unique adapter oligonucleotides to the first-strand cDNA. The unique adapters can then be used to prime the PCR amplification and the generation of double-stranded cDNA. The advantage of this procedure is that it allows the generation of large amounts of cDNA from limited quantities of RNA. Due to the utilization of PCR, however, some of the cDNAs may not be amplified as efficiently as others and may thus be lost from the SSH starting material. A similar inability to identify all expected known genes after a differential screen was recently reported by others and ascribed to the

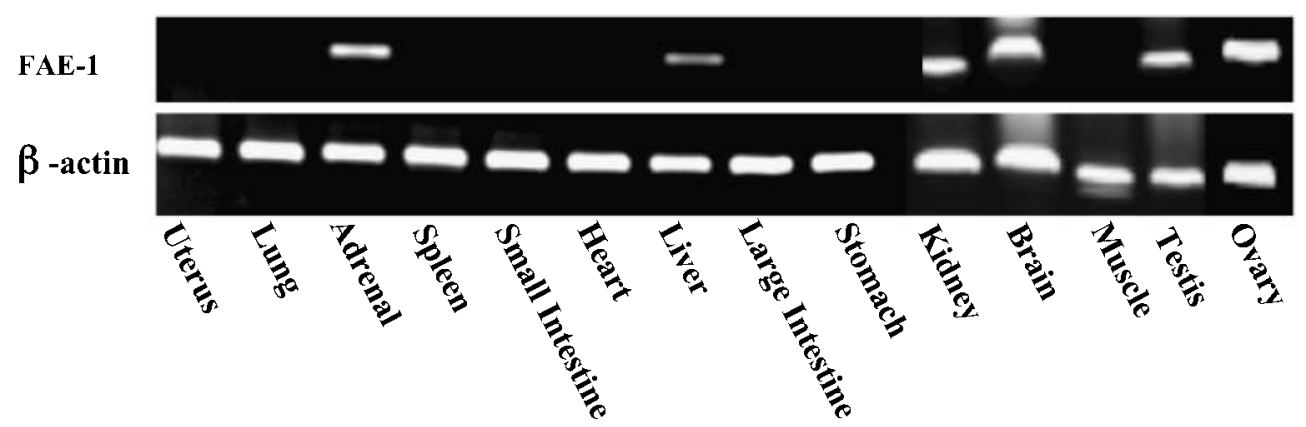

Figure 5 Semiquantitative RT-PCR amplification of FAE-1 homolog CDNAs in 14 different mouse tissues. The resultant PCR product was separated on a 1.5\% agarose gel and stained with ethidium bromide. The panel reflects a representative experiment from a total of three independent experiments. 


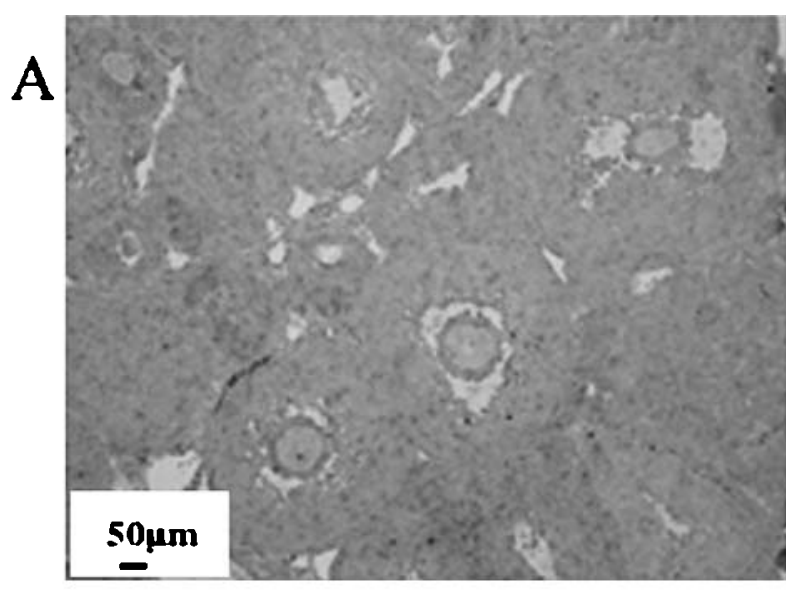

Oh hCG

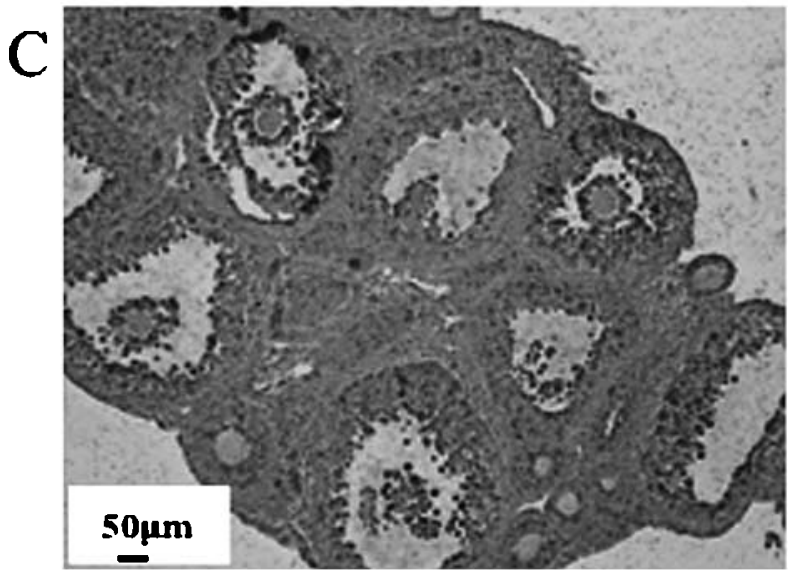

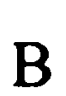

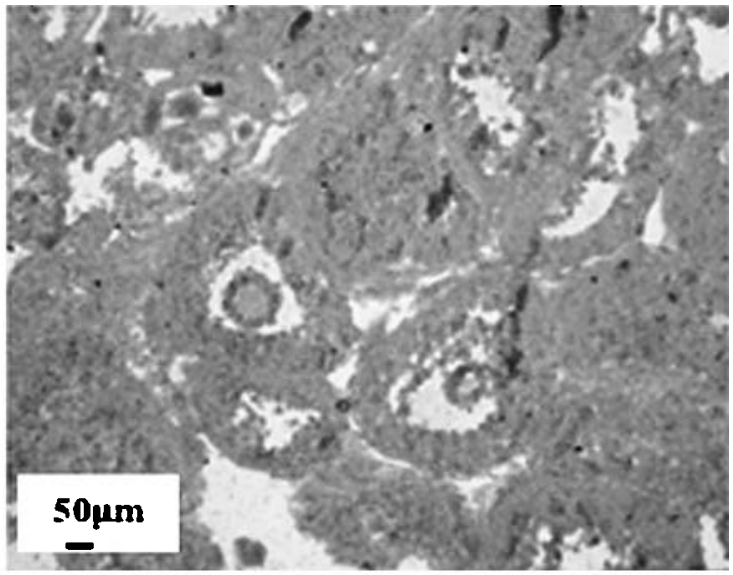

$4 \mathrm{~h} \mathrm{hCG}$

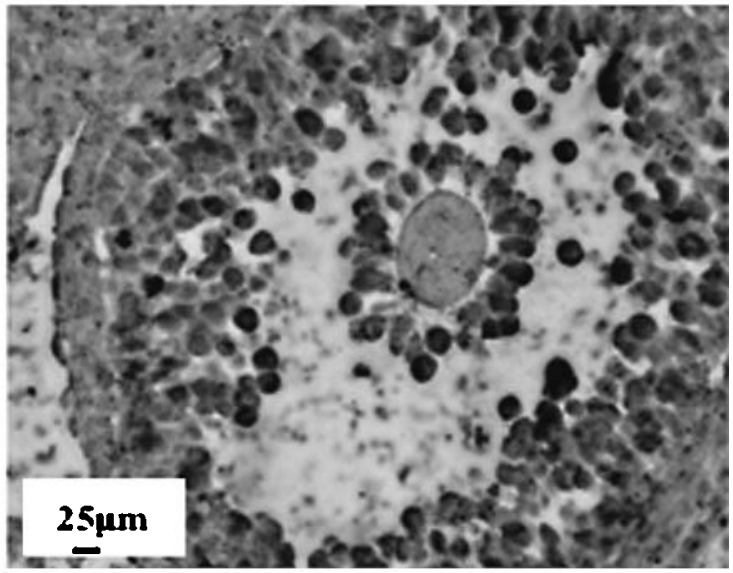

\section{$8 \mathrm{~h} \mathrm{hCG}$}

Figure 6 In situ hybridization analysis with a FAE-1 homolog DIG-labeled CRNA probe in ovaries of immature, 25-day-old

PMSG/hCG-stimulated mice. Brightfield photomicrographs depict the distribution of DIG-labeled probe. (A) 48-h post-PMSG (0-h hCG) ovary displays no labeling. (B) 4-h post-hCG reveals a weak positive signal in some granulosa cells, only in a few follicles. (C) 8-h post-hCG discloses a strong signal in granulosa cells of the antral follicles. Magnification $\times 4$. (D) Closer view of the distribution of FAE-1 homolog cRNA probe in a representative follicle $8 \mathrm{~h}$ after hCG administration. The FAE-1 cRNA probe hybridizes to the granulosa and cumulus cells surrounding the oocytes. Magnification $\times 20$.

incomplete representation of the total cDNA repertoire (den Hollander et al. 1999, Tanaka et al. 2003).

The ovulatory cDNAs isolated from the (subtracted/ SSH-generated) library included several cDNAs that have previously been reported to be involved in the murine ovulatory process (Espey \& Richards 2002). Examples include StAR (Espey \& Richards 2002), 3ß-HSDI, early growth response protein-1 (Espey et al. 2000a), epiregulin (Espey \& Richards 2002), cathepsin-L (Robker et al. $2000 a, 2000 b)$ and tumor necrosis factor-stimulated gene-6 (Brannstrom et al. 1994, Yoshioka et al. 2000). During the validation process, $26 \%$ of the tested cDNA could not be detected by the Northern blot technique. This negative outcome may reflect the low level of sensitivity of the Northern blot methodology employed, as compared with the capability of the $\mathrm{SSH}$ technique, to identify low abundant genes. Verification of ovulationselective or -specific expression of these 25 negative clones will require the use of a more sensitive methodology, such as real-time RT-PCR. Thirty clones were expressed at a same or higher level in the 48-h PMSG (preovulatory) ovarian mRNA relative to the post-hCG (ovulatory) mRNA, giving a false-positive rate of $41 \%$. This rate is within the accepted range of the reported false-positive rate for the $\mathrm{SSH}$ technique, as it varies very much depending on experimental circumstances (Lee et al. 2000, Tanaka et al. 2003, Fayad et al. 2004).

In this report, we chose to focus on FAE-1 as a representative of a new ovulation-selective gene. FAE-1 was found to increase significantly after an ovulatory dose 
of hCG, reaching a peak 8-12 h after hCG, when follicles first begin to rupture. FAE-1 (FAE1, SSC 1, ELOVL 1) is a $\beta$-ketoacyl-CoA synthase that belongs to the ELO family. The ELO family consists of eukaryotic, evolutionarily related, integral membrane proteins involved in fatty acid elongation. As these genes were identified only recently, not much is known on their function. The family includes the mammalian proteins ELOVL1-4 (Tvrdik et al. 2000) and the yeast proteins ELO1-3 (Oh et al. 1997). They seem to be components of membranebound, fatty acid elongation systems that catalyze the initial step of very long-chain fatty acids and produce the 26-carbon precursors for ceramide and sphingolipid synthesis (Oh et al. 1997). According to the ExPASy protein analysis tools, they may catalyze one or both of the reduction reactions in fatty acid elongation, that is, conversion of beta-ketoacyl CoA to beta-hydroxyacyl CoA or reduction of trans-2-enoyl CoA to the saturated acyl CoA derivative. The proteins have 271-435 amino-acid residues. Specifically, FAE-1 consists of 299 amino acids. Structurally, they seem to be formed of three sections: an $\mathrm{N}$-terminal region with two transmembrane domains, a central hydrophilic loop and a C-terminal region that contains from one to three transmembrane domains.

The PSORT (http://psort.nibb.ac.jp:8000) cellular localization prediction algorithm suggests that FAE-1 is an endoplasmic reticulum (ER)-associated protein (reliability: 94.1), containing a KKXX-like motif in its $\mathrm{C}$-terminus that is an ER membrane retention signal. The related gene, yeast ELO3, affects plasma membrane $\mathrm{H}(+)$ ATPase activity, and may act on a glucose-signaling pathway that controls the expression of several genes that are transcriptionally regulated by glucose, such as PMA1.

It has been previously shown that the metabolism of membrane sphingolipids (such as sphingomyelin or ceramide) may be an important regulatory pathway in the control of steroid metabolism and steroid hormone synthesis (Sender Baum \& Ahren 1988, Hattori \& Horiuchi 1992, Degnan et al. 1996, Budnik et al. 1999, Soboloff et al. 1999). It has also been shown that in cultured fibroblasts, exogenous sphingomyelinase decreases cholesterol synthesis (Degnan et al. 1996). Moreover, LH-receptor expression is modulated by gangliosidespecific ligands (Lee et al. 1977, Chatelain et al. 1979, Hattori et al. 1994). We therefore suggest that FAE-1 may be involved in the regulation of steroid hormone synthesis during the ovulation process through the action of sphingolipid synthesis. Another role for FAE-1 may be related to a protective effect from carbon fragments formed in the ovary during or after ovulation. It was reported (O'Meara et al. 1985) that elongation of essential fatty acids by the ovary is an important mechanism in disposing of carbon fragments generated by the incomplete oxidation of fatty acids during steroidogenesis. The ovarian level of FAE-1 returns to the nonsignificant control levels at $24 \mathrm{~h}$ after hCG, confirming FAE-1 as a representative of an early gene response to gonadotropic hormone action on the ovulatory follicle. The dose of indomethacin that inhibited ovulation did not block the transcription of mRNA for this enzyme. Moreover, the early expression of the gene, before the ovulatory peak in PG production, suggests that prostanoid synthesis is not required for the induction of FAE-1 ovarian expression. However, this does not exclude a role for this enzyme in the ovulatory process, since the gonadotropin-induced expression of FAE-1 can be either a direct effect preceding the prostanoid expression or one mediated through ovarian steroids. The signal localized chiefly in the inner periantral granulosa (that is, granulosa cells adjacent to the antrum) and cumulus granulosa cells of developing antral follicles may suggest a role in follicular development. Further studies are needed to elucidate the exact role of this gene in the ovulation process.

In summary, this work demonstrates that the $\mathrm{SSH}$ technique can be used to identify new hCG-induced genes suspected to be involved in the ovulatory process. These ovulation-selective/specific genes may contribute to a better understanding of the molecular mechanisms of ovulation, and to the development of new strategies for either the promotion of fertility or its control.

\section{Acknowledgements}

We thank Dr Shifra Ben-Dor for help in bioinformatics analysis. This study was supported in part by grants from the Women's Health Research Center, Weizmann Institute of Science (N D); the Chief Scientist Office, Israel Ministry of Health (N D); the Israel Scientific Foundation $(\mathrm{N} \mathrm{D})$; and the US National Institutes of Health research grants HD 37845 (E Y A), HD 42000 and RR 00163 (J D H). The authors declare that there is no conflict of interest that would prejudice the impartiality of this scientific work.

\section{References}

Brannstrom M, Norman RJ, Seamark RF \& Robertson SA 1994 Rat ovary produces cytokines during ovulation. Biology of Reproduction 50 88-94.

Budnik LT, Jahner D \& Mukhopadhyay AK 1999 Inhibitory effects of TNF alpha on mouse tumor Leydig cells: possible role of ceramide in the mechanism of action. Molecular and Cellular Endocrinology 150 39-46.

Chatelain P, Deleers M, Poss A \& Ruysschaert JM 1979 A specific GT1 ganglioside-luteinizing hormone interaction induces conductance changes in lipid bilayers. Experientia 35 334-335.

Chee M, Yang R, Hubbell E, Berno A, Huang XC, Stern D, Winkler J, Lockhart DJ, Morris MS \& Fodor SP 1996 Accessing genetic information with high-density DNA arrays. Science 274 610-614

Davis BJ, Lennard DE, Lee CA, Tiano HF, Morham SG, Wetsel WC \& Langenbach R 1999 Anovulation in cyclooxygenase-2-deficient mice is restored by prostaglandin $\mathrm{E}_{2}$ and interleukin-1 beta. Endocrinology $1402685-2695$. 
Degnan BM, Bourdelat-Parks B, Daniel A, Salata K \& Francis GL 1996 Sphingomyelinase inhibits in vitro Leydig cell function. Annals of Clinical Laboratory Science 26 234-242.

den Hollander AI, van Driel MA, de Kok YJ, van de Pol DJ, Hoyng CB, Brunner HG, Deutman AF \& Cremers FP 1999 Isolation and mapping of novel candidate genes for retinal disorders using suppression subtractive hybridization. Genomics 58 240-249.

Diatchenko L, Lau YF, Campbell AP, Chenchik A, Moqadam F, Huang B, Lukyanov S, Lukyanov K, Gurskaya N, Sverdlov ED et al. 1996 Suppression subtractive hybridization: a method for generating differentially regulated or tissue-specific cDNA probes and libraries. PNAS 93 6025-6030.

Diatchenko L, Lukyanov S, Lau YF \& Siebert PD 1999 Suppression subtractive hybridization: a versatile method for identifying differentially expressed genes. Methods in Enzymology 303 349-380.

Espey LL 1980 Ovulation as an inflammatory reaction - a hypothesis. Biology of Reproduction 22 73-106.

Espey LL \& Richards JS 2001 Gonadotropin-induced expression of inflammation-related genes during ovulation in the rat. Abstract M29. Biology of Reproduction 64 96-97.

Espey LL \& Richards JS 2002 Temporal and spatial patterns of ovarian gene transcription following an ovulatory dose of gonadotropin in the rat. Biology of Reproduction 67 1662-1670.

Espey LL, Ujioka T, Russell DL, Skelsey M, Vladu B, Robker RL, Okamura H \& Richards JS 2000a Induction of early growth response protein-1 gene expression in the rat ovary in response to an ovulatory dose of human chorionic gonadotropin. Endocrinology 141 2385-2391.

Espey LL, Yoshioka S, Russell D, Ujioka T, Vladu B, Skelsey M, Fujii S, Okamura H \& Richards JS 2000b Characterization of ovarian carbonyl reductase gene expression during ovulation in the gonadotropin-primed immature rat. Biology of Reproduction 62 390-397.

Espey LL, Yoshioka S, Russell DL, Robker RL, Fujii S \& Richards JS 2000c Ovarian expression of a disintegrin and metalloproteinase with thrombospondin motifs during ovulation in the gonadotropin-primed immature rat. Biology of Reproduction 62 1090-1095.

Espey LL, Yoshioka S, Ujioka T, Fujii S \& Richards JS 2001 3 alpha-hydroxysteroid dehydrogenase messenger RNA transcription in the immature rat ovary in response to an ovulatory dose of gonadotropin. Biology of Reproduction 65 72-78.

Fayad T, Levesque V, Sirois J, Silversides DW \& Lussier JG 2004 Gene expression profiling of differentially expressed genes in granulosa cells of bovine dominant follicles using suppression subtractive hybridization. Biology of Reproduction 70 523-533.

Hattori M \& Horiuchi R 1992 Biphasic effects of exogenous ganglioside GM3 on follicle-stimulating hormone-dependent expression of luteinizing hormone receptor in cultured granulosa cells. Molecular and Cellular Endocrinology 88 47-54.

Hattori M, Kanzaki M, Kojima I \& Horiuchi R 1994 Granulosa cell luteinizing hormone receptor expression is modulated by ganglioside-specific ligands. Biochimica et Biophysica Acta $122147-53$.

Leo CP, Pisarska MD \& Hsueh AJ 2001 DNA array analysis of changes in preovulatory gene expression in the rat ovary. Biology of Reproduction 65 269-276.

Lee G, Aloj SM \& Kohn LD 1977 The structure and function of glycoprotein hormone receptors: ganglioside interactions with luteinizing hormone. Biochemical and Biophysical Research Communications 77 434-441.

Lee KF, Kwok KL \& Yeung WS 2000 Suppression subtractive hybridization identifies genes expressed in oviduct during mouse preimplantation period. Biochemical and Biophysical Research Communications 277 680-685.

Levesque V, Fayad T, Ndiaye K, Nahe Diouf M \& Lussier JG 2003 Size-selection of cDNA libraries for the cloning of cDNAs after suppression subtractive hybridization. Biotechniques 35 72-78.
Lim H, Paria BC, Das SK, Dinchuk JE, Langenbach R, Trzaskos JM \& Dey SK 1997 Multiple female reproductive failures in cyclooxygenase 2-deficient mice. Cell 91 197-208.

Lisitsyn N \& Wigler M 1993 Cloning the differences between two complex genomes. Science 259 946-951.

Lydon JP, DeMayo FJ, Funk CR, Mani SK, Hughes AR, Montgomery CA Jr, Shyamala G, Conneely OM \& O'Malley BW 1995 Mice lacking progesterone receptor exhibit pleiotropic reproductive abnormalities. Genes and Development 9 2266-2278.

Lydon JP, DeMayo FJ, Conneely OM \& O'Malley BW 1996 Reproductive phenotypes of the progesterone receptor null mutant mouse. Journal of Steroid Biochemistry and Molecular Biology 56 67-77.

Matzuk MM \& Lamb DJ 2002 Genetic dissection of mammalian fertility pathways. Nature Medicine 8 S33-S40.

Matzuk MM, Kumar TR \& Bradley A 1995 Different phenotypes for mice deficient in either activins or activin receptor type II. Nature 374 356-360.

Oh CS, Toke DA, Mandala S \& Martin CE 1997 ELO2 and ELO3, homologues of the Saccharomyces cerevisiae ELO1 gene, function in fatty acid elongation and are required for sphingolipid formation. Journal of Biological Chemistry 272 17376-17384.

O’Meara ML, Tuckey RC \& Stevenson PM 1985 A comparison of the lipid classes and essential fatty acid content of rat plasma lipoproteins and ovary. International Journal of Biochemistry 17 1027-1030.

Pall M, Hellberg P, Brannstrom M, Mikuni M, Peterson CM, Sundfeldt K, Norden B, Hedin L \& Enerback S 1997 The transcription factor $\mathrm{C} / \mathrm{EBP}-$ beta and its role in ovarian function; evidence for direct involvement in the ovulatory process. EMBO Journal 16 5273-5279.

Rankin TL, Tong ZB, Castle PE, Lee E, Gore-Langton R, Nelson LM \& Dean J 1998 Human ZP3 restores fertility in Zp3 null mice without affecting order-specific sperm binding. Development $1252415-2424$

Rebrikov DV, Desai SM, Siebert PD \& Lukyanov SA 2004 Suppression subtractive hybridization. Methods in Molecular Biology 258 107-134.

Richards JS 1994 Hormonal control of gene expression in the ovary. Endocrine Reviews 15 725-751.

Richards JS, Fitzpatrick SL, Clemens JW, Morris JK, Alliston T \& Sirois J 1995 Ovarian cell differentiation: a cascade of multiple hormones, cellular signals, and regulated genes. Recent Progress in Hormone Research 50 223-254.

Richards JS, Russell DL, Robker RL, Dajee M \& Alliston TN 1998 Molecular mechanisms of ovulation and luteinization. Molecular and Cellular Endocrinology 145 47-54.

Richards JS, Russell DL, Ochsner S \& Espey LL 2002a Ovulation: new dimensions and new regulators of the inflammatory-like response. Annual Reviews in Physiology 64 69-92.

Richards JS, Russell DL, Ochsner S, Hsieh M, Doyle KH, Falender AE, Lo YK \& Sharma SC $2002 b$ Novel signaling pathways that control ovarian follicular development, ovulation, and luteinization. Recent Progress in Hormone Research 57 195-220.

Robker RL, Russell DL, Espey LL, Lydon JP, O’Malley BW \& Richards JS 2000a Progesterone-regulated genes in the ovulation process: ADAMTS-1 and cathepsin L proteases. PNAS 97 4689-4694.

Robker RL, Russell DL, Yoshioka S, Sharma SC, Lydon JP, O'Malley BW, Espey LL \& Richards JS 2000b Ovulation: a multi-gene, multi-step process. Steroids 65 559-570.

Sambrook J, Fritsch EF \& Maniatis T 1989 Northern hybridization. In Molecular Cloning, a Laboratory Manual, pp 7-39-37-52. Ed C Nolan. Cold Spring Harbor, NY, USA: Cold Spring Harbor Laboratory Press.

Schena M, Shalon D, Davis RW \& Brown PO 1995 Quantitative monitoring of gene expression patterns with a complementary DNA microarray. Science $270467-470$. 
Sender Baum MG \& Ahren KE 1988 Sphingosine and psychosine, suggested inhibitors of protein kinase $\mathrm{C}$, inhibit $\mathrm{LH}$ effects in rat luteal cells. Molecular and Cellular Endocrinology 60 127-135.

Soboloff J, Sorisky A, Desilets M \& Tsang BK 1999 Acyl chain length-specific ceramide-induced changes in intracellular $\mathrm{Ca}^{2+}$ concentration and progesterone production are not regulated by tumor necrosis factor alpha in hen granulosa cells. Biology of Reproduction 60 262-271.

Sterneck E, Tessarollo L \& Johnson PF 1997 An essential role for C/EBPbeta in female reproduction. Genes and Development 11 2153-2162.

Tanaka M, Hennebold JD, Miyakoshi K, Teranishi T, Ueno K \& Adashi EY 2003 The generation and characterization of an ovary-selective cDNA library. Molecular and Cellular Endocrinology 202 67-69.

Tvrdik P, Westerberg R, Silve S, Asadi A, Jakobsson A, Cannon B, Loison G \& Jacobsson A 2000 Role of a new mammalian gene family in the biosynthesis of very long chain fatty acids and sphingolipids. Journal of Cell Biology 149 707-718.
Ujioka T, Russell DL, Okamura H, Richards JS \& Espey LL 2000 Expression of regulator of G-protein signaling protein-2 gene in the rat ovary at the time of ovulation. Biology of Reproduction 63 1513-1517.

Velculescu VE, Zhang L, Vogelstein B \& Kinzler KW 1995 Serial analysis of gene expression. Science 270 484-487.

Wang X \& Feuerstein GZ 2000 Suppression subtractive hybridisation: application in the discovery of novel pharmacological targets. Pharmacogenomics 1 101-108.

Yoshioka S, Ochsner S, Russell DL, Ujioka T, Fujii S, Richards JS \& Espey LL 2000 Expression of tumor necrosis factor-stimulated gene- 6 in the rat ovary in response to an ovulatory dose of gonadotropin. Endocrinology 141 4114-4119.

Received 22 November 2005

Accepted 17 December 2005 